\title{
Composição florística da vegetação altimontana do distrito de Monte Verde (Camanducaia, MG), Serra da Mantiqueira Meridional, Sudeste do Brasil ${ }^{1}$
}

Floristic composition of high-montane vegetation in the district of Monte Verde (Camanducaia, Minas Gerais), Serra da Mantiqueira Meridional, Southeast Brasil

Leonardo Dias Meireles ${ }^{2,4}$, Luiza Sumiko Kinoshita ${ }^{3} \&$ George John Shepherd ${ }^{3}$

\begin{abstract}
Resumo
A Serra da Mantiqueira apresenta um mosaico de formações vegetacionais composto por florestas altimontanas, florestas de araucária, campos de altitude e afloramentos rochosos. Realizamos um levantamento florístico nas formações altimontanas do distrito de Monte Verde, Camanducaia, MG, Sudeste do Brasil, para quantificarmos a riqueza específica de cada formação e analisarmos a distribuição geográfica das espécies. Foram coletadas 499 espécies, distribuídas entre 97 famílias e 285 gêneros. As famílias com maior riqueza específica foram Asteraceae (77 espécies), Melastomataceae e Orchidaceae (25), Myrtaceae (24), Solanaceae (23), Cyperaceae e Fabaceae (22), e Rubiaceae (18). Os gêneros mais ricos foram Baccharis (16 espécies), Solanum (15), Leandra (10), Myrceugenia (9), Tibouchina (8) e Myrcia (7). Registramos a ocorrência de três espécies recém-descritas e cinco novos registros para o estado de Minas Gerais. Cerca de 60 espécies são exclusivas do Sudeste brasileiro, enquanto 124 ocorrem também na região Sul. A presença de espécies endêmicas e com distribuição geográfica restrita destaca a influência da Serra da Mantiqueira na distribuição de espécies vegetais no Domínio da Floresta Atlântica. Palavras-chave: floresta atlântica, florestas altimontanas, florestas de araucária, campos de altitude, afloramentos rochosos.
\end{abstract}

\begin{abstract}
The Serra da Mantiqueira mountain range harbors a mosaic of high-mountain vegetation composed of upper montane forests, Araucária forests, high-altitude grasslands and rocky outcrops. A floristic survey was carried out in the upper montane formations of Monte Verde district, Camanducaia, in the State of Minas Gerais, southeastern Brazil, to quantify the richness of each formation, and analyze the geographic distribution of species. A total of 499 species was collected, distributed among 97 families and 285 genera. The richest families were Asteraceae (77 species), Melastomataceae and Orchidaceae (25), Myrtaceae (24), Orchidaceae (23), Solanaceae (23), Cyperaceae and Fabaceae (22), and Rubiaceae (18). The richest genera were Baccharis (16 species), Solanum (15), Leandra (10), Myrceugenia (9), Tibouchina (8), and Myrcia (7). The occurrence of three newly described species and five new records for Minas Gerais state were observed. About 60 species occur only in the southeast of Brazil, while 124 also occur in the southern region of Brazil. The occurrence of endemic species and species with narrow geographic distribution showed the influence of the Serra da Mantiqueira mountain chain on the distribution of plant species in the Atlantic Forest Domain.
\end{abstract}

Key words: Atlantic rain forest, upper montane forests, araucaria forests, high altitude grasslands, rocky outcrop.

\footnotetext{
${ }^{1}$ Parte da dissertação de Mestrado do primeiro autor.

${ }^{2}$ Universidade de São Paulo, Escola de Artes, Ciências e Huminades, Curso de Gestão Ambiental, Av. Arlindo Béttio 1000, 03828-000, São Paulo, SP, Brasil

${ }^{3}$ Universidade Estadual de Campinas, Inst. Biologia, Depto. Biologia Vegetal, R. Monteiro Lobato 255, C.P. 6109, 13.083-970, Campinas, SP, Brasil.

${ }^{4}$ Autor para correspondência: leodmeireles@gmail.com
} 


\section{Introdução}

A Serra da Mantiqueira corresponde ao segundo degrau ao leste do Planalto Brasileiro e, com seu destacado desnível altitudinal, influencia fortemente o relevo e as condições climáticas da região Sudeste brasileira (Moreira \& Camelier 1977; Almeida \& Carneiro 1998). Em conjunto com a Serra do Mar, representa o orobioma mais frio e úmido do leste da América do Sul, o que proporciona mudanças na composição e na estrutura das formações florestais e campestres no Domínio da Floresta Atlântica (Segadas-Viana \& Dau 1965; Safford 1999).

A Floresta Atlântica no Sudeste brasileiro encontra-se bastante fragmentada e áreas relativamente contínuas estão restritas às encostas de cadeias montanhosas (Galindo-Leal \& Câmara 2005). Na Serra da Mantiqueira persiste cerca de $20 \%$ da cobertura florestal atlântica remanescente no estado de Minas Gerais, na divisa com os estados de São Paulo e Rio de Janeiro (Costa \& Herrmann 2006). Sua porção meridional, composta pelo Planalto de Campos de Jordão e pelo Planalto do Itatiaia, apresenta um desnível altitudinal entre 1.000 a 2.000 metros de altitude e uma considerável extensão de formações vegetacionais altimontanas (Moreira \& Camelier 1977).

A vegetação no Planalto de Campos de Jordão está composta por florestas ombrófilas densas montanas e alto-montanas, florestas ombrófilas mistas alto-montanas, estepes (campos de altitude), afloramentos rochosos e pequenos fragmentos de savana (cerrado) (Azevedo 1962). Na cimeira desse planalto a vegetação caracteriza-se por um mosaico dessas fitofisionomias. Os campos recobrem os topos de interflúvio, bem como o setor convexo das vertentes, e as matas ocupam o setor retilíneo inferior das vertentes convexas, as vertentes retilíneas e os anfiteatros de erosão (Himura et al. 2001).

Esse complexo vegetacional está imerso em uma matriz vegetacional composta pela floresta estacional semidecidual do sul de Minas de Gerais, a oeste em direção ao interior, e pela floresta ombrófila densa montana do Vale do Paraíba, no estado de São Paulo, ao leste (Hueck 1972; Berg \& Oliveira-Filho 2000). A dificuldade de acesso e o baixo potencial madeireiro e a criação de Unidades de Conservação atrasaram uma destruição intensa desse complexo vegetacional, o que contribui para a conservação de áreas florestadas e campestres em algumas regiões de altitude da Serra da Mantiqueira (Costa et al. 1998). Entretanto, principalmente a floresta montana, parte da floresta alto-montana e os fragmentos campestres no distrito de Monte Verde foram substituídos por pastagens, reflorestamentos monoculturais, construções urbanas, ou ainda sofreram intenso corte madeireiro (Golfari 1975).

Azevedo (1962) reconheceu variações fitofisionômicas decorrentes de condições diversas - clima, solos, altitude, relevo e duração da estação seca - para formações florestais ao sul da Serra da Mantiqueira. A destacada variação altitudinal observada na região promove uma diminuição na pressão atmosférica que propicia um aumento na precipitação e uma maior incidência de neblina, bem como uma diminuição nas temperaturas mínimas, aumentando a probabilidade de ocorrências de geadas no período de menor precipitação (Segadas-Viana \& Dau 1965; Safford 1999). Esses fatores abióticos afetam tanto o funcionamento da vegetação altimontana quanto a distribuição geográfica e a extensão de ocorrência de espécies vegetais no Domínio da Floresta Atlântica (Oliveira-Filho \& Fontes 2000).

A Serra da Mantiqueira é considerada uma Área de Importância Biológica Especial (Costa \& Herrmann 2006), devido ao elevado nível de endemismos para plantas, anfíbios e répteis, além de uma alta diversidade de aves e pequenos mamíferos (Dusén 1955; Brade 1956; Willis 1996). A região de Camanducaia - Monte Verde, pertencente ao Planalto de Campos de Jordão, também é reconhecida como uma área de importância biológica muito alta devido à ocorrência de plantas endêmicas, mamíferos e aves ameaçados de extinção (Costa et al. 1998).

A região Sudeste brasileira representa um dos centros de diversidade da Floresta Atlântica e várias das suas áreas de altitude ainda não possuem levantamentos florísticos publicados ou foram pouco inventariadas (Shepherd 1995, Martinelli 2007). Este levantamento florístico tem como objetivo verificar quais espécies de espermatófitas compõem a vegetação altimontana do distrito de Monte Verde e quantificar a riqueza específica e a composição florística de suas fitofisionomias. A distribuição geográfica das espécies também foi analisada para identificarmos padrões de distribuição de espécies ocorrentes nesse complexo vegetacional altimontano da Serra da Mantiqueira. 


\section{Material e Métodos}

Área de Estudo

O distrito de Monte Verde, do município de Camanducaia, no estado de Minas Gerais, está inserido ao sul da Serra da Mantiqueira Meridional, na divisa com o estado de São Paulo, nas coordenadas geográficas $22^{\circ} 51^{\prime} \mathrm{S}$ e $46^{\circ} 02^{\prime} \mathrm{W}$ (Fig. 1). Possui cotas altitudinais que variam de 1.550 a 2.082 metros acima do nível do mar. A Serra da Mantiqueira é denominada na região como "Serra dos Poncianos", que corresponde a uma das unidades geomorfológicas que compõem o Planalto de Campos do Jordão. A Pedra do Selado, a $2.082 \mathrm{~m}$ de altitude, juntamente com o Platô (1.900 m), o Chapéu do Bispo (2.030 m), a Pedra Redonda (1.990 m) e a Pedra Partida, a 2.050 $\mathrm{m}$, são os principais picos e platôs de rocha aflorada da Serra da Mantiqueira nessa região.

Essa região era conhecida como Campos do Jaguari, pela proximidade das nascentes do Rio Jaguari, em Sapucaí Mirim, que com seu afluente, o rio Camanducaia, compõe o sistema "Cantareira" de abastecimento de água para o estado de São Paulo (Barbi 2007). Na década de 1930, iniciou-se a ocupação humana com a instalação da Fazendo Pico do Selado. O primeiro loteamento de parte da Fazenda ocorreu na década de 1950. Desde essa época, sua vegetação tem sofrido impacto por atividades agropastoris e madeireiras e pelo plantio de monoculturas de gimnospermas exóticas. Na década de 1990, o distrito tornou-se um importante polo turístico, intensificando o impacto antrópico sobre a vegetação. A criação da APA Fernão Dias, em 1997, tem incentivado atividades conservacionistas na região (Costa \& Hermann 2006).

O clima, no sistema de Köeppen, é do tipo Cwb (subtropical de altitude), com verões amenos e chuvosos e invernos frios e mais secos com ocorrência de geadas (Martins 2000). A precipitação média anual, entre os anos de 1971 e 2001, foi de $1.740 \mathrm{~mm}$ e variou entre 1.380 $\mathrm{mm}$ a $2.360 \mathrm{~mm}$. A temperatura máxima média, entre julho de 2001 e julho de 2002, variou nos meses quentes e úmidos (outubro a março) entre 26,3 e $29,7^{\circ} \mathrm{C}$ e, enquanto a temperatura mínima média variou nos meses frios e secos (abril a setembro) de 3 a $9,9^{\circ} \mathrm{C}$. Durante esse período foram observados oito dias com ocorrência de geadas (dados medidos pela Companhia Melhoramentos Florestal S/A). Machado-Filho et al. (1983) registraram a ocorrência de cambissolos álicos nas áreas mais elevadas e latossolos vermelho-amarelos distróficos nas áreas mais baixas na região do distrito de Monte Verde.

Para a denominação das formações florestais utilizamos IBGE (2012) e para as formações campestres Semir (1991). Foram reconhecidas dentre as formações florestais a Floresta Ombrófila Densa Alto-montana e a Floresta Ombrófila Mista Alto-montana; e dentre as formações campestres os Afloramentos Rochosos e Campos de Altitude. A Floresta Ombrófila Densa Alto-montana (Floresta Altimontana - Fig. 2a-b) localiza-se entre 1.500$1.600 \mathrm{~m}$ e $2.000 \mathrm{~m}$ de altitude e esteve constituída por mesofanerófitos, com um dossel variando entre nove e $20 \mathrm{~m}$ de altura e apresenta uma alta densidade de indivíduos. As árvores, na sua maioria, apresentam fuste pouco desenvolvido, verificandose um acentuado epifitismo avascular em seus troncos. O estrato herbáceo-arbustivo apresentou-se pouco denso a denso. A Floresta Ombrófila Mista Alto-montana (Floresta de Araucária - Fig. 2c) localizou-se entre $1.500 \mathrm{~m}$ e $1.650 \mathrm{~m}$ de altitude e geralmente sobre um relevo plano-ondulado, associada com cursos d'água. Esteve constituída por mesofanerófitos que formam um dossel que alcança até 20 m, com indivíduos emergentes de Araucaria angustifolia. Um estrato intermediário composto por arvoretas pode ser observado, além de um estrato arbustivo-herbáceo pouco denso.

Os Campos de Altitude localizaram-se acima de $1.500 \mathrm{~m}$, desenvolvendo-se principalmente nas áreas mais planas e formando brejos em áreas com drenagem dificultada. Apresentam um estrato herbáceo dominado por gramíneas e um estrato arbustivo constituído por arbustos e arvoretas esparsas. Os Afloramentos Rochosos (Fig. 2d) corresponderam a áreas de rochas granitoides expostas, onde as plantas se estabelecem em ilhas de vegetação ou nas frestas das rochas. Essas ilhas apresentam uma matriz formada por briófitas, liquens e monocotiledôneas, sobre as quais se estabelecem outras ervas e pequenos arbustos.

\section{Metodologia de Coleta e Listagem Florística}

O levantamento florístico foi realizado através de caminhadas entre março de 2001 e março de 2003, com visitas de dois a cinco dias, quinzenalmente no início das coletas e mensalmente no final das coletas. Coletas esporádicas em anos posteriores também foram realizadas. Entre 2001 e 2003, foram realizadas 15 expedições de coletas na Floresta Altimontana 


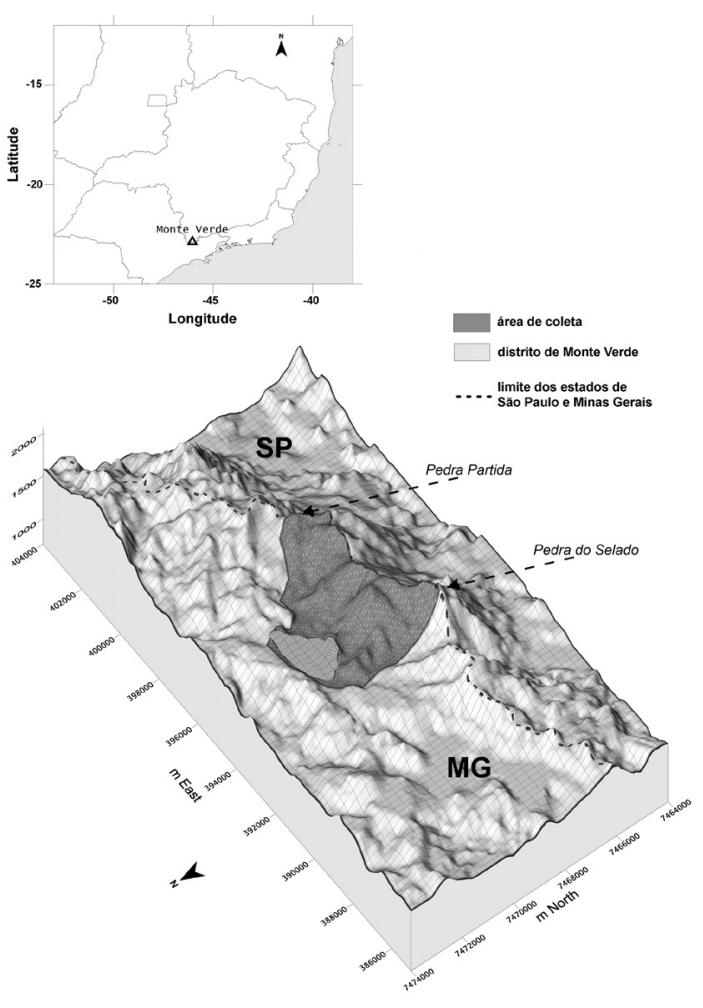

Figura 1 - Localização geográfica e mapa com relevo do distrito de Monte Verde, Camanducaia, Minas Gerais. Área de coleta: compreende a área entre a Pedra Partida e o Pico do Selado até as adjacências da área urbana do distrito de Monte Verde.

Figure 1-Geographical location and relief map of Monte Verde district, Camanducaia, State of Minas Gerais. Collection area: comprises the area between the Pedra Partida Peak and Pedra do Selado Peak down to the adjacent urban area of the Monte Verde district.

e nos Afloramentos Rochosos ao longo da cadeia principal da Serra da Mantiqueira (Fig. 1), que incluíram quatro visitas às três áreas de Floresta de Araucária, com coletas esporádicas nos campos de altitude em várias dessas viagens. Uma coleta específica a uma pequena área de campo de altitude, imerso dentro da Floresta Altimontana na região da Pedra da Onça, foi realizada, mas mesmo essa área isolada apresentava forte impacto por atividades silvipastoris passadas. Os indivíduos em estádio reprodutivo foram coletados e as exsicatas foram depositadas no herbário da Universidade Estadual de Campinas (UEC) e duplicatas distribuídas entre herbários do Sudeste brasileiro.

A identificação das espécies foi realizada com auxílio da literatura especializada, consulta a especialistas e por meio de comparação com outros materiais identificados em coleções científicas. Para a elaboração da listagem florística, a classificação em famílias foi baseada em Angiosperm Phylogeny Group III (APG III 2009). Para a grafia dos nomes científicos e nomenclatura de gêneros seguiu-se a nomenclatura proposta na Lista de Espécies da Flora do Brasil (Forzza et al. 2012). Posteriormente para evitar erros na grafia dos epípetos genéricos e específicos utilizamos o Pacote 'flora' (Carvalho 2104).

O hábito das espécies foi definido pelo porte, grau de lignificação dos ramos e troncos e pelo sistema radicular. O hábito arbóreo foi utilizado para indivíduos lenhosos, perenes, com fuste usualmente único, ramificado acima de $1 \mathrm{~m}$ do nível do solo, ou composto por fustes múltiplos, ramificados ao nível do solo, mas totalmente lignificados, e com sistema radicular axial lignificado. $\mathrm{O}$ hábito arbustivo foi definido como indivíduos lenhosos, perenes com fuste único ou múltiplos, ramificados ao nível do solo ou até 1 metro de altura e com sistema radicular axial pouco ou muito lignificado. $\mathrm{O}$ hábito bambusóide correspondeu a indivíduos constituídos por colmos lenhosos com rizoma e sistema radicular adventício. O hábito herbáceo foi definido como indivíduos não lenhosos, rosulados ou caule pouco lignificado, eretos, decumbentes ou prostrados, podendo apresentar rizoma, bulbo ou cormo e sistema radicular axial, adventício ou fasciculado. Trepadeiras foram consideradas indivíduos com ramos flexíveis ou volúveis que se apoiam sobre outros vegetais, passivamente ou por meio de órgãos preensores e com sistema radicular fixo ao solo. O hábito epifítico inclui as espécies que vegetam sobre outros indivíduos vegetais, utilizando-os apenas como suporte, com sistema radicular independente do solo e o hábito parasítico como as plantas que crescem sobre outro vegetal nutrindo-se da sua seiva, apresentado ou não sistema radicular (modificado a partir de Font Quer 1975 e Vidal \& Vidal 1995).

\section{Distribuição geográfica}

A distribuição geográfica das espécies foi obtida por consulta à literatura taxonômica (teses, revisões, trabalhos florísticos e floras regionais) e complementada por informações encontradas em sites especializados como speciesLink (CRIA 2001), $w^{3}$ Tropicos (MBG 2014), The C.V. Starr Virtual Herbarium (NYBG 1996-2004) e Lista 

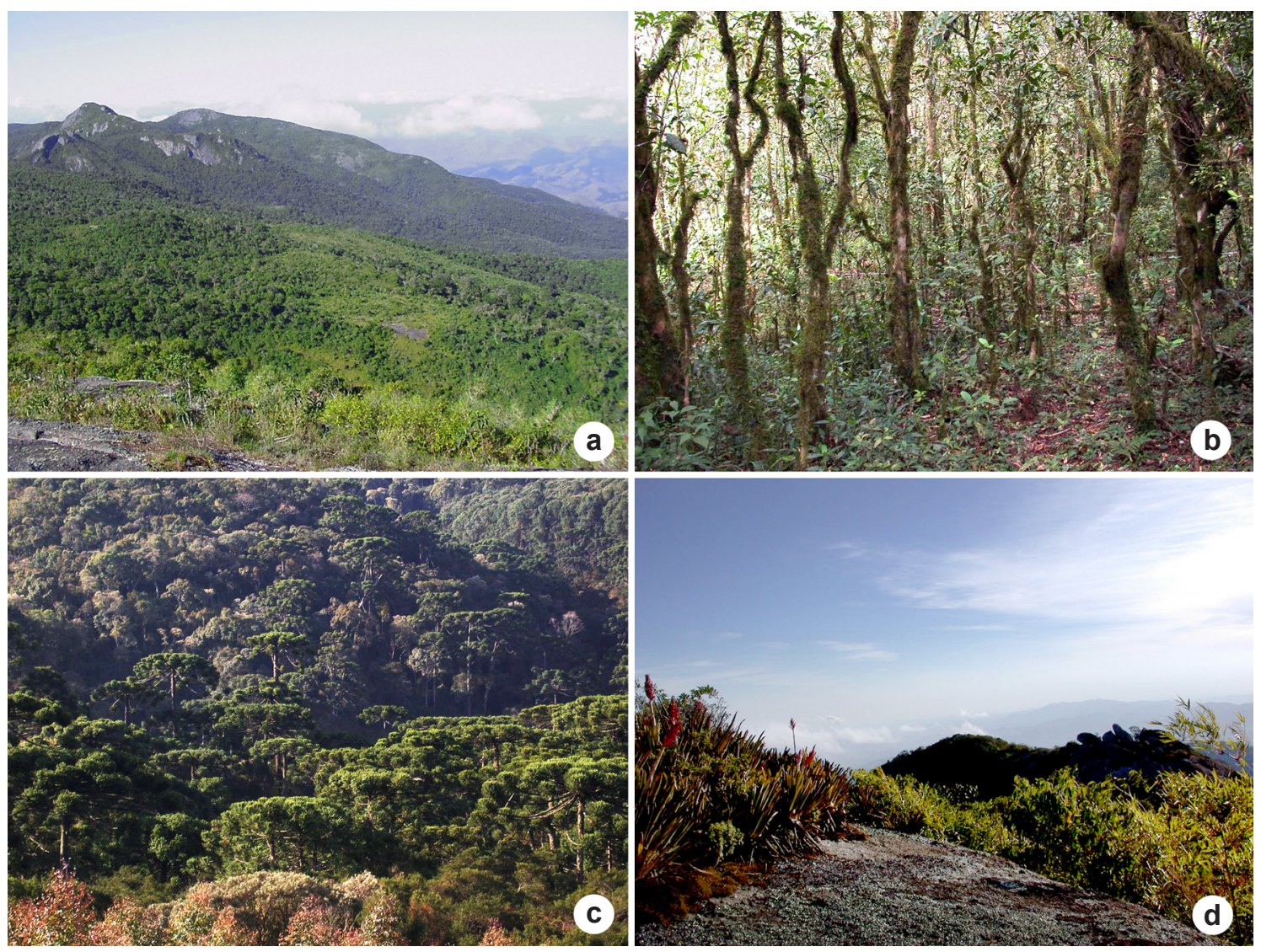

Figura 2 - Fisionomia das formações vegetacionais ocorrentes no distrito de Monte Verde, Camanducaia, Minas Gerais. a. vista panorâmica da Floresta Altimonta; b. vista panorâmica do interior da Floresta Altimontana; c. vista panorâmica da Floresta de Araucária; d. vista panorâmica dos Afloramentos Rochosos.

Figure 2 - Physiognomies of vegetacional types in the Monte Verde district, Camanducaia, State of Minas Gerais. a. panoramic view of Upper Montane Forest; b. panoramic view inside of Upper Montane Forest; c. panoramic view of Araucária Forest; d. panoramic view of Rocky Outcrops.

de Espécies da Flora do Brasil (Forzza et al. 2012). As espécies que ocorrem somente no território brasileiro receberam siglas para as regiões geográficas brasileiras (Sul: S; Sudeste: Se; Centro-Oeste: CO; Nordeste: Ne; Norte: N). Para as espécies que ocorrem em países do Cone Sul (Argentina, Paraguai e Uruguai) foi adicionada a sigla $\mathrm{CS}$.

Entre as espécies distribuídas pela região Sudeste (SE), distinguiu-se quatro subgrupos de endemismo em ordem crescente de extensão de ocorrência a partir do Planalto de Campos do Jordão: SE (CJ) - espécies restritas ao Planalto de Campos de Jordão; SE (MM) - espécies restritas à Serra da Mantiqueira Meridional, ocorrentes também no Planalto do Itatiaia; SE (ML) espécies observadas em formações montanas das cadeias montanhosas litorâneas do Sudeste; e SE (CR) - espécies ocorrentes em campos rupestres.
Dentre as espécies distribuídas pelas Regiões Sudeste e Sul do país (S-SE), distinguiu-se dois sub-grupos: S-SE (FA) - espécies restritas às florestas altimontanas das áreas de altitude litorâneas do Sul e Sudeste; e S-SE (PS) - aquelas amplamente distribuídas pelos planaltos sulinos e que não ocorrem em formações ombrófilas densa nas encostas da Serra do Mar.

A distribuição geográfica das espécies que ocorrem além do território brasileiro foi classificada como: Américas - (América): espécies americanas ocorrentes além da Região Neotropical; Neotropical - (Neotrop.): as espécies ocorrentes ao longo da Região Neotropical; América do Sul - (AmSul): aquelas ocorrentes amplamente no território da América do Sul; Andes - (Andes): espécies observadas em formações tropicais e/ou sub-tropicais montanos ao longo da Cordilheira Andina. 


\section{Resultados}

Foram coletadas 499 espécies, distribuídas entre 95 famílias e 285 gêneros (Tab. 1). Destas 111 espécies (22,1\%) eram arbóreas, 133 (26,7\%) arbustivas, $193(38,7 \%)$ herbáceas, duas $(0,4 \%)$ bambusóides, $35(7,1 \%)$ trepadeiras, $22(4,4 \%)$ epífitas e três $(0,6 \%)$ parasitas. As famílias com maior riqueza específica foram Asteraceae (77 espécies), Melastomataceae e Orchidaceae (25 cada), Myrtaceae (24), Solanaceae (23), Cyperaceae e Fabaceae (22 cada) e Rubiaceae (18). Os gêneros mais ricos foram Baccharis (16 espécies), Solanum (15), Leandra (10), Myrceugenia (nove), Tibouchina (oito) e Myrcia (sete).

Na Floresta Altimontana, foram coletadas 291 espécies, distribuídas entre 80 famílias e 186 gêneros, sendo que 220 espécies foram exclusivas dessa formação em Monte Verde. Do total de espécies, 95 espécies eram árboreas, 66 arbustivas, duas bambusóides, 82 herbáceas, 31 trepadeiras, 12 epífitas e três parasitas (Tab. 1). As famílias mais ricas foram Asteraceae (43 espécies), Myrtaceae (18), Solanaceae (16), Melastomataceae (13), Orchidaceae (11), Rubiaceae (10) e Lauraceae (nove). Os gêneros mais ricos foram Solanum (12 espécies), Baccharis, Leandra e Myrcengenia (sete cada), Peperomia (seis espécies cada), enquanto Ilex, Myrcia, Ocotea e Vernonanthura apresentaram cinco espécies cada.

$\mathrm{Na}$ Floresta de Araucária foram coletadas 91 espécies, distribuídas em 50 famílias e 77 gêneros, sendo 45 espécies exclusivas a essa formação. Do total de espécies, 37 eram arbóreas, 25 arbustivas, 13 herbáceas, quatro trepadeiras e 12 epífitas (Tab. 1). Solanaceae (nove espécies), Myrtaceae (oito), Asteraceae (sete), Orchidaceae (seis) e Rubiaceae (cinco) apresentaram a maior riqueza específica. Myrcia e Solanum (cinco espécies cada) foram os gêneros mais ricos; os demais gêneros apresentaram uma ou duas espécies.

Nos Campos de Altitude foram coletadas 129 espécies, distribuídas entre 45 famílias e 95 gêneros, com 96 espécies exclusivas a essa formação. Desse total, 53 eram arbustivas, cinco arbóreas e 71 herbáceas (Tab. 1). As famílias mais ricas foram Asteraceae (27 espécies) e Fabaceae (14), seguidas de Cyperaceae (oito), Iridaceae (sete) e Melastomataceae (cinco). Baccharis (sete espécies) e Sisyrinchium (quatro) foram os gêneros mais ricos, além de Carex, Desmodium, Gaylussacia, Mimosa, Paepalanthus, Polygonum, Rhynchospora e Tibouchina que apresentaram três espécies cada.
Nos Afloramentos Rochosos foram coletadas 87 espécies, pertencentes a 34 famílias e 67 gêneros, com 58 espécies exclusivas. Do total de espécies, 20 eram arbustivas, 66 herbáceas e uma trepadeira (Tab. 1). As famílias mais ricas foram Asteraceae (10 espécies), Cyperaceae e Melastomataceae (nove espécies cada) e Orchidaceae (oito), além de Polygalaceae e Rubiaceae com cinco espécies cada. Tibouchina (cinco espécies) foi o gênero mais rico, seguido por Polygala (quatro), e Bulbostilys e Habenaria com três espécies cada.

O número de espécies compartilhadas entre as formações variou entre seis a 40 espécies, enquanto a quantidade de espécies exclusivas a uma formação variou entre 45 a 220 espécies (Tab. 2). Caamembeca insignis, Croton dichrous, Fuchsia regia e Leptostelma maximum foram as únicas espécies que ocorreram nas quatro formações amostradas (Tab. 1). As espécies restritas a região Sudeste brasileira (61) representaram 12,2\% da riqueza total, e foram mais frequentes na Floresta Altimontanas e nos Afloramentos Rochosos (Tab. 3). Dessas, cinco espécies foram endêmicas do Planalto de Campos de Jordão, nove espécies restritas à Mantiqueira Meridional, enquanto 32 espécies foram observadas somente nas florestas e campos altimontanos litorâneos e nove observadas somente em campos rupestres do Sudeste. Outras cinco espécies (1\%) restringiramse ao Sudeste e ao Centro-Oeste, enquanto outras seis $(1,2 \%)$ restringiram-se às Regiões Sudeste e Nordeste. Cerca de $26,4 \%$ do total de espécies (132) distribuiu-se também em formações florestais e campestres montanas da Região Sul, Sudeste, Nordeste e/ou Centro-Oeste e Norte (Tab. 3).

As espécies que ocorreram exclusivamente na Região Sul e Sudeste (126) representaram 25,4\% do total de espécies coletadas. As proporções de espécies com esse padrão geográfico variaram entre 23,1 a 29,7\% entre as formações, mas apresentaram maior riqueza na Floresta Altimontana. Cerca de $3,4 \%$ (17 espécies) estiveram restritas às formações altimontanas litorâneas do Sul e Sudeste e 49 espécies $(9,8 \%)$ ocorreram também em formações florestais e campestres planálticas da região Sul. Outras 21 espécies $(4,2 \%)$ também ocorreram em formações montanas e/ou temperadas andinas, ao passo que $60(12 \%)$ apresentaram distribuição neotropical e $20(4,1 \%)$ estiveram distribuídas somente na América do Sul, enquanto 19 (3,9\%) ocorreram pelo continente americano. Quatorze espécies $(2,9 \%)$ foram consideradas exóticas e/ou subespontâneas (Tab 3). 
Tabela 1 - Listagem das espécies coletadas no levantamento florístico das formações altimontanas do distrito de Monte Verde, Camanducaia, Serra da Mantiqueira Meridional, Minas Gerais. Hábito: Ab: Arbustivo; Av: Arbóreo; Bb: Bambusóide; Hb: Herbáceo, Ep: Epífita; Tp: Trepadeira; Pt: Parasita. Formação: Formações vegetacionais - $(F A)$ Floresta Altimontana; $(A R)$ Floresta de Araucária; $(A F)$ Afloramento Rochoso; $(C A)$ Campos de Altitude. Distr. Geogr. (Distribuição geográfica): S: Sul; SE: Sudeste; CO: Centro-Oeste; NE: Nordeste; N: Norte; CJ: endêmica do Planalto de Campos do Jordão; MM: endêmica da Serra da Mantiqueira Meridional; ML: restrita às áreas de altitude litorâneas do Sudeste, CR: ocorrentes em campos rupestres; CS: países do Cone Sul; FA: restritas às formações altimontanas do Sul e Sudeste; PS: ocorrentes nas formações altimontanas do Sudeste e nos planaltos sulinos; Neotrop.: Neotropical; AmSul: América do Sul; Ex: Exótica. Coleções: LDM: Leonardo Dias Meireles; LSK: Luzia Sumiko Kinoshita; MME: Marcelo Monge-Egea; WMF: Washington Marcondes Ferreira; HFL: Hermógenes Freitas Leitão-Filho; ASF: Andréa Silva Flores; JLAMF: João Luiz Mazza Aranha-Filho; UEC: Herbário da Universidade de Campinas; NCF: não coletada fértil.

Table 1 - Checklist of species sampled in floristic survey of upper montane vegetation in Monte Verde district, Camanducaia, Mantiqueira Meriodional Mountain Range, State of Minas Gerais. Habit: Ab: Shrub; Av: Tree; Bb: woody bamboo; Ep: Epiphyte; Ev: Herb; Tp: Climber; Pt: Parasite. Vegetacional Types: $(F A)$ Upper montane forest; $(A R)$ Araucaria forest; $(A F)$ Rocky outcrop; $(C A)$ High-altitude grasslands. Distr. Geogr. (Geographical Distribution): S: South, SE: Southeast, CO: Midwest, NE: Northeast, N: Northern; CJ: endemic to Campos do Jordão Plateau, MM: endemic to Mantiqueira Meriodional Mountain Range; ML: restricted to high-altitude coastal areas of the Southeast, CR: occurring in rocky outcrop grasslands; CS: southern Cone countries; FA: restricted to the south and southeast upper montane formations; PS: restricted to upper montane formations of the southeast and south highland plateau; Neotrop.: Neotropical; AmSul: South America; Ex: Exotic. Collections: LDM: Leonardo Dias Meireles; LSK: Luzia Sumiko Kinoshita; MME: Marcelo MongeEgea; WMF: Washington Marcondes Ferreira; HFL: Hermógenes Freitas Leitão-Filho, ASF: Andrea Silva Flores; JLAMF: João Luiz Mazza Aranha-Filho; UEC: Herbarium of the University of Campinas; NCF: not collected fertile.

\begin{tabular}{|c|c|c|c|c|}
\hline Família/Espécie & Hábito & Distr. Geogr. & Fisionomia & No. coletor \\
\hline \multicolumn{5}{|l|}{ Alstroemeriaceae } \\
\hline Alstroemeria cunha Vell. & $\mathrm{Ev}$ & S-SE-NE & $F A$ & LDM 873 \\
\hline Alstroemeria isabelleana Herb. & $\mathrm{Ev}$ & S-SE-CO & $A F$ & LDM 693 \\
\hline Bomarea edulis Herb. & $\mathrm{Ev}$ & Neotrop. & $F A$ & UEC 64.157 \\
\hline \multicolumn{5}{|l|}{ Amaranthaceae } \\
\hline Alternanthera brasiliana (L.) Kuntze & $\mathrm{Ev}$ & AmSul & $F A$ & LDM 964 \\
\hline Hebanthe eriantha (Poir.) Pederson & Ev & AmSul & $F A$ & LDM 1154 \\
\hline Hebanthe pulverulenta Mart. & $\mathrm{Ev}$ & S-SE-CO & $F A$ & LDM 1203 \\
\hline Iresine diffusa Humb. \& Bonpl. & Ev & Neotrop. & $F A$ & LDM 965 \\
\hline \multicolumn{5}{|l|}{ Amaryllidaceae } \\
\hline Hippeastrum morelianum Lem. & Ev & SE (ML) & $A F$ & LDM 349 \\
\hline \multicolumn{5}{|l|}{ Anacardiaceae } \\
\hline Schinus polygamus (Cav.) Cabrera & $\mathrm{Av}$ & Andes & $A R, C A$ & LDM 526 \\
\hline \multicolumn{5}{|l|}{ Annonaceae } \\
\hline Guatteria australis A.St.-Hil. & $\mathrm{Av}$ & S-SE-NE-CO & $F A$ & LDM 723 \\
\hline Annona emarginata (Schltdl.) H.Rainer & Av & S-SE-NE-CO & $F A, A R$ & LDM 1033 \\
\hline \multicolumn{5}{|l|}{ Apiaceae } \\
\hline Eryngium eburneum Decne. & $\mathrm{Ev}$ & AndNorte & $A F$ & LDM 875 \\
\hline Eryngium proliferum Brade & $\mathrm{Ev}$ & SE (ML) & $F A$ & LDM 861 \\
\hline \multicolumn{5}{|l|}{ Apocynaceae } \\
\hline Aspidosperma olivaceum Müll.Arg. & Av & S-SE-NE & $F A$ & LDM 735 \\
\hline Mandevilla emarginata (Vell.) C.Ezcurra & $\mathrm{Ev}$ & S-SE-CO & $C A$ & UEC 57221 \\
\hline Orthosia urceolata E.Fourn. & Ln & S-SE (CS) & $F A$ & LDM 491 \\
\hline Oxypetalum glabrum (Decne.) Malme & Ln & S-SE (FA) & $F A$ & LDM 650 \\
\hline Oxypetalum regnellii (Malme) T.Mey. & Ln & SE (ML) & $F A$ & LDM 317 \\
\hline \multicolumn{5}{|l|}{ Aquifoliaceae } \\
\hline Ilex dumosa Reissek & $\mathrm{Av}$ & S-SE-NE-CO & $F A, A R, C A$ & LDM 812 \\
\hline Ilex microdonta Reissek & $\mathrm{Av}$ & S-SE (PS) & $F A$ & $\mathrm{NCF}$ \\
\hline
\end{tabular}




\begin{tabular}{|c|c|c|c|c|}
\hline Família/Espécie & Hábito & Distr. Geogr. & Fisionomia & No. coletor \\
\hline Ilex paraguariensis A.St.-Hil. & $\mathrm{Av}$ & S-SE-NE-CO & $F A, A R$ & LDM 484 \\
\hline Ilex taubertiana Reissek & $\mathrm{Av}$ & S-SE (FA) & $F A$ & LDM 788 \\
\hline Ilex theezans Mart. ex Reissek & $\mathrm{Av}$ & S-SE-NE-CO (CS) & $F A$ & LDM 634 \\
\hline \multicolumn{5}{|l|}{ Araceae } \\
\hline Asterostigma colubrinum Schott & Ev & SE & $F A$ & LDM 1183 \\
\hline Asterostigma lividum (Lodd.) Engl. & Ev & SE & $F A$ & LDM 739 \\
\hline \multicolumn{5}{|l|}{ Araliaceae } \\
\hline Hydrocotyle itatiaiensis Brade & Ev & S-SE (FA) & $F A$ & LDM 848 \\
\hline Hydrocotyle leucocephala Cham. \& Schltdl. & Ev & Neotrop. & $F A$ & LDM 862 \\
\hline Hydrocotyle quinqueloba Ruiz \& Pav. & Ev & AndNorte & $F A$ & LDM 849 \\
\hline Oreopanax fulvus Marchal & Av & S-SE (PS) & $F A$ & $\mathrm{NCF}$ \\
\hline Schefflera calva (Cham.) Frodin & $\mathrm{Av}$ & S-SE-CO & $F A$ & LDM 1062 \\
\hline \multicolumn{5}{|l|}{ Araucariaceae } \\
\hline Araucaria angustifolia (Bertol.) Kuntze & $\mathrm{Av}$ & S-SE (PS) & $A R$ & $\mathrm{NCF}$ \\
\hline \multicolumn{5}{|l|}{ Asteraceae } \\
\hline Achyrocline alata DC. & $\mathrm{Ev}$ & AndNorte & $F A, A F, C A$ & LDM 1032 \\
\hline Achyrocline satureioides (Lam.) DC. & Ev & AmSul & $C A$ & MME 474 \\
\hline Aspilia foliacea Baker & $\mathrm{Ev}$ & S-SE-CO-N & $C A$ & LDM 542 \\
\hline $\begin{array}{l}\text { Austroeupatorium inulaefolium (Kunth) R.M.King } \\
\text { \& H.Rob. }\end{array}$ & $\mathrm{Ab}$ & S-SE-NE-CO & $F A$ & LDM 1027 \\
\hline $\begin{array}{l}\text { Austroeupatorium silphiifolium (Mart.) R.M.King \& } \\
\text { H.Rob. }\end{array}$ & $\mathrm{Ab}$ & S-SE-NE-CO & $F A$ & LDM 1002 \\
\hline Baccharis anomala DC. & $\mathrm{Ab}$ & S-SE (CS) & $C A$ & LDM 3382 \\
\hline Baccharis breviseta DC. & $\mathrm{Ab}$ & S-SE-NE-CO & $C A$ & LDM 986 \\
\hline Baccharis caprariifolia DC. & $\mathrm{Ab}$ & S-SE & $F A$ & LDM 1011 \\
\hline Baccharis crispa Spreng. & Ev & S-SE-NE-CO & $F A$ & LDM 408 \\
\hline Baccharis dentata (Vell.) G.M.Barroso & $\mathrm{Ab}$ & S-SE-NE-CO & $F A$ & LDM 1003 \\
\hline Baccharis grandimucronata Malag. & $\mathrm{Ab}$ & S-SE (FA) & $F A, A F$ & LDM 446 \\
\hline Baccharis hirta DC. & Ev & S-SE (CS) & $A F$ & LDM 882 \\
\hline Baccharis lateralis Baker & $\mathrm{Ab}$ & S-SE (PS) & $C A$ & LDM 1194 \\
\hline Baccharis mesoneura DC. & $\mathrm{Ab}$ & S-SE & $C A$ & LDM 529 \\
\hline Baccharis cf. microcephala (Less.) DC. & $\mathrm{Ev}$ & - & $C A$ & LSK 106/02 \\
\hline Baccharis montana DC. & $\mathrm{Ab}$ & S-SE (PS) & $F A$ & LDM 1187 \\
\hline Baccharis oreophila Malme & Av & S-SE (PS) & $F A$ & LDM 353 \\
\hline Baccharis regnellii Sch.Bip. ex Baker & $\mathrm{Ab}$ & SE-NE & $C A$ & LDM 689 \\
\hline Baccharis reticularia DC. & $\mathrm{Ab}$ & S-SE-NE-CO & $F A, C A$ & LDM 457 \\
\hline Baccharis retusa DC. & $\mathrm{Ab}$ & S-SE-NE-CO & $A R$ & MME 058 \\
\hline Baccharis vulneraria Baker & $\mathrm{Ab}$ & S-SE (CS) & $F A$ & WMF 1723 \\
\hline Bidens segetum Mart. ex Colla & $\mathrm{Ab}$ & Neotrop. & $F A$ & LDM 951 \\
\hline Calea serrata Less. & Ln & SE-CO & $F A$ & LDM 387 \\
\hline $\begin{array}{l}\text { Campuloclinium purpurascens (Sch.Bip. ex Baker) } \\
\text { R.M.King \& H.Rob. }\end{array}$ & $\mathrm{Ab}$ & S-SE & $C A$ & LDM 984 \\
\hline Chaptalia integerrima (Vell.) Burkat & Ev & S-SE-NE-CO (CS) & $C A$ & LDM 549 \\
\hline Chaptalia nutans (L.) Polak. & Ev & Neotrop. & $F A$ & LDM 627 \\
\hline Chevreulia sarmentosa (Pers.) S.F.Blake & $\mathrm{Ev}$ & Neotrop. & $C A$ & LDM 1233 \\
\hline Chromolaena stachyophylla R.M.King \& H.Rob. & Ev & S-SE-NE-CO & $C A$ & LDM 553 \\
\hline Chrysolaena obovata (Less.) Dematt. & $\mathrm{Ev}$ & Neotrop. & $C A$ & LDM 558 \\
\hline Conyza sumatrensis (Retz.) E.Walker & Ev & Neotrop. & $F A$ & LDM 1012 \\
\hline Dasyphyllum flagellare (Casar.) Cabrera & $\mathrm{Ab}$ & S-SE-CO & $F A$ & LDM 275 \\
\hline
\end{tabular}




\begin{tabular}{|c|c|c|c|c|}
\hline Família/Espécie & Hábito & Distr. Geogr. & Fisionomia & No. coletor \\
\hline Dasyphyllum tomentosum (Less.) Cabrera & Av & S-SE (PS) & $F A$ & LDM 497 \\
\hline $\begin{array}{l}\text { Dendrophorbium pellucidinerve (Sch. Bip. ex Baker) } \\
\text { C.Jeffrey }\end{array}$ & $\mathrm{Ab}$ & SE (ML) & $A F$ & LDM 396 \\
\hline Erechtites valerianifolius (Wolf) DC. & $\mathrm{Ev}$ & Neotrop. & $F A, C A$ & LDM 410 \\
\hline Eupatorium alpestre Gardn. & $\mathrm{Ab}$ & S-SE (PS) & $F A$ & LDM 276 \\
\hline Exostigma notobellidiastrum (Griseb.) G.Sancho & $\mathrm{Ev}$ & S-SE-CO & $F A$ & LDM 1192 \\
\hline Gamochaeta americana (Mill.) Wedd. & $\mathrm{Ev}$ & Neotrop. & $F A$ & LDM 713 \\
\hline Gamochaeta cf. hiemalis (Rizzini) Cabrera & $\mathrm{Ab}$ & - & $F A, C A$ & LDM 970 \\
\hline Grazielia intermedia (DC.) R.M.King \& H.Rob. & $\mathrm{Ab}$ & S-SE-CO & $C A$ & LDM 989 \\
\hline Heterocondylus alatus (Vell.) R.M.King \& H.Rob. & $\mathrm{Ab}$ & S-SE-NE-CO & $F A$ & LDM 1152 \\
\hline Hypochaeris chillensis (Kunth) Briton & Ev & Andes & $C A$ & WMF 1728 \\
\hline Hypochaeris gardneri Baker & Ev & S-SE & $A F$ & LDM 705 \\
\hline Jaegeria hirta (Lag.) Less. & Ev & Neotrop. & $F A$ & LDM 423 \\
\hline Lepidaploa salzmannii (DC.) H.Rob. & $\mathrm{Ab}$ & Neotrop. & $F A$ & LDM 963 \\
\hline Leptostelma maximum D.Don & Ev & S-SE (CS) & $F A, A R, A F, C A$ & LDM 426 \\
\hline Lessingianthus cephalotes (DC.) H.Rob. & $\mathrm{Ev}$ & SE-CO & $C A$ & LDM 543 \\
\hline Lessingianthus macrophyllus (Less.) H.Rob. & Ev & S-SE-NE & $A R$ & LDM 398 \\
\hline Mikania camporum B.L.Rob. & Ln & SE (MM) & $F A$ & LDM 1022 \\
\hline Mikania hemisphaerica DC. & Ln & S-SE-NE (CS) & $A R$ & LDM 999 \\
\hline Mikania lasiandrae DC. & Ln & S-SE-CO & $F A$ & LDM 1059 \\
\hline Mikania cf. sericea Hook. \& Arn. & Ln & - & $F A$ & LDM 1021 \\
\hline Mikania ternata (Vell.) B.L.Rob. & Ln & S-SE-NE & $F A$ & LDM 1044 \\
\hline Mutisia campanulata Less. & Ln & S-SE (CS) & $F A$ & LDM 348 \\
\hline Mutisia coccinea A.St.-Hil. & Ln & S-SE (CS) & $F A$ & UEC 64.918 \\
\hline Mutisia speciosa Aiton ex Hook. & Ln & S-SE (CS) & $F A$ & UEC 64.158 \\
\hline Ophryosporus sp. & $\mathrm{Ab}$ & - & $C A$ & LDM s/n \\
\hline Pentacalia desiderabilis (Vell.) Cuatrec. & $\mathrm{Ab}$ & S-SE-NE & $F A, A F$ & LDM 482 \\
\hline Piptocarpha axillaris (Less.) Baker & Av & S-SE-CO & $F A$ & LDM 366 \\
\hline Piptocarpha regnellii (Sch.Bip.) Cabrera & $\mathrm{Av}$ & S-SE (FA) & $F A$ & $\mathrm{NCF}$ \\
\hline Senecio hemmendorffii Malme & $\mathrm{Ab}$ & S-SE (FA) & $A R$ & LDM 532 \\
\hline Senecio brasiliensis (Spreng.) Less. & $\mathrm{Ab}$ & S-SE (CS) & $C A$ & LDM 1227 \\
\hline Senecio erisithalifolius Sch.Bip. ex Baker & Ev & SE & $C A$ & WMF 1727 \\
\hline Senecio icoglossus DC. & $\mathrm{Ev}$ & S-SE-CO & $A F$ & LDM 397 \\
\hline Stenocephalum tragiaefolium (DC.) Sch.Bip. & $\mathrm{Ev}$ & SE-CO & $C A$ & LDM 557 \\
\hline Stevia decussata Baker & $\mathrm{Ab}$ & $\mathrm{SE}(\mathrm{CR})$ & $A F$ & LDM 008 \\
\hline Symphyotrichum squamatum (Spreng.) G.L.Nesom & Ev & Neotrop. & $C A$ & LDM 3378 \\
\hline Tagetes minuta $\mathrm{L}$. & $\mathrm{Ab}$ & America & $C A$ & LDM 3389 \\
\hline Tagetes patula $\mathrm{L}$. & $\mathrm{Ab}$ & Ex & $C A$ & LSK 100/02 \\
\hline Trixis praestans (Vell.) Cabr. & $\mathrm{Ab}$ & S-SE & $A R$ & LDM 439 \\
\hline Trixis verbascifolia (Gardner) Blake & $\mathrm{Ab}$ & $\mathrm{SE}(\mathrm{CR})$ & $F A$ & LDM 303 \\
\hline Verbesina glabrata Hook. \& Arn. & $\mathrm{Ab}$ & S-SE-NE & $F A$ & LDM 765 \\
\hline Vernonanthura discolor (Spreng.) H.Rob. & Av & S-SE-NE (CS) & $F A$ & LDM 1554 \\
\hline Vernonanthura divaricata (Spreng.) H.Rob. & $\mathrm{Av}$ & S-SE-NE & $F A, A R$ & LDM 437 \\
\hline Vernonanthura montevidensis (Spreng.) H.Rob. & $\mathrm{Ab}$ & S-SE (CS) & $C A$ & LDM 1215 \\
\hline Vernonanthura petiolaris (DC.) H.Rob. & $\mathrm{Ab}$ & S-SE-CO & $F A$ & LDM 438 \\
\hline Vernonanthura phaeoneura (Toledo) H.Rob. & $\mathrm{Ab}$ & SE (ML) & $F A$ & LDM 1008 \\
\hline Vernonanthura puberula (Less.) H.Rob. & Av & S-SE & $F A$ & LDM 347 \\
\hline \multicolumn{5}{|l|}{ Begoniaceae } \\
\hline Begonia angulata Vell. & Ev & S-SE (PS) & $F A$ & LDM 1015 \\
\hline
\end{tabular}




\begin{tabular}{|c|c|c|c|c|}
\hline Família/Espécie & Hábito & Distr. Geogr. & Fisionomia & No. coletor \\
\hline Begonia cucullata Willd. & Ev & S-SE-NE-CO (CS) & $F A, C A$ & LDM 981 \\
\hline Begonia fruticosa A.DC. & Ep & S-SE-NE & $F A$ & LDM 1204 \\
\hline \multicolumn{5}{|l|}{ Berberidaceae } \\
\hline Berberis laurina Billb. & $\mathrm{Ab}$ & S-SE (CS) & $A R, C A$ & LDM 1250 \\
\hline \multicolumn{5}{|l|}{ Bignoniaceae } \\
\hline Amphilophium magnoliifolium (Kunth) L.G.Lohmann & Ln & S-SE-NE-CO-N & $A R$ & LDM 824 \\
\hline Handroanthus albus (Cham.) Mattos & $\mathrm{Av}$ & S-SE (CS) & $F A$ & LDM 458 \\
\hline Jacaranda puberula Cham. & Av & SE & $F A, A R$ & LDM 733 \\
\hline Zeyheria montana Mart. & $\mathrm{Ab}$ & S-SE-NE-CO-N & $C A$ & HLF 1863 \\
\hline \multicolumn{5}{|l|}{ Brasicaceae } \\
\hline Cardamine africana $\mathrm{L}$. & Ev & Ex & $F A$ & LDM 1207 \\
\hline \multicolumn{5}{|l|}{ Bromeliaceae } \\
\hline Aechmea distichantha Lem. & Ev & S-SE-CO (CS) & $F A, A F$ & LDM 351 \\
\hline Billbergia distachia (Vell.) Beer & Ep & S-SE & $F A$ & LDM 432 \\
\hline Edmundoa lindenii (Regel) Leme & Ep & S-SE & $F A$ & LDM 431 \\
\hline Nidularium innocentii Lem. & $\mathrm{Ev}$ & S-SE-NE & $F A, A F$ & LDM 434 \\
\hline Pitcairnia flammea Lindl. & Ev & S-SE-NE & $A F$ & LDM 651 \\
\hline Tillandsia stricta Sol. ex Sims & Ep & AmSul & $A R$ & LDM 1259 \\
\hline Vriesea bituminosa Wawra & Ev & SE (ML) & $F A$ & LDM 1029 \\
\hline Vriesea pardalina $\mathrm{Mez}$ & Ep & SE & $A R$ & LDM 1176 \\
\hline \multicolumn{5}{|l|}{ Cactaceae } \\
\hline $\begin{array}{l}\text { Hatiora herminiae (Porto \& A.Cast.) Backeb. ex } \\
\text { Barthlott }\end{array}$ & Ev & $\mathrm{SE}(\mathrm{CJ})$ & $F A, A F$ & LDM 480 \\
\hline Hatiora salicornioides (Haw.) Britton \& Rose & Ep & S-SE-NE & $A R$ & LDM 825 \\
\hline Rhipsalis floccosa Salm-Dyck ex Pfeiff. & Ep & AndNorte & $F A, A R$ & LDM 476 \\
\hline \multicolumn{5}{|l|}{ Campanulaceae } \\
\hline Lobelia exaltata Pohl & $\mathrm{Ev}$ & S-SE & $C A$ & LDM 832 \\
\hline Siphocampylus longipedunculatus Pohl & $\mathrm{Ab}$ & $\mathrm{SE}(\mathrm{ML})$ & $F A$ & LDM 1004 \\
\hline Siphocampylus umbellatus (Kunth) G.Don & $\mathrm{Ab}$ & AndNorte & $F A$ & LDM 465 \\
\hline Siphocampylus macropodus (Thunb.) G.Don & $\mathrm{Ab}$ & S-SE-CO & $C A$ & LDM 441 \\
\hline Siphocampylus westinianus (Thunb.) Pohl & $\mathrm{Ab}$ & SE-CO & $C A$ & LDM 1308 \\
\hline \multicolumn{5}{|l|}{ Caprifoliaceae } \\
\hline Sambucus cf. australis Cham. \& Schltdl. & $\mathrm{Ab}$ & Ex & $A R$ & LDM 813 \\
\hline Valeriana scandens $\mathrm{L}$. & Ln & Neotrop. & $F A$ & LDM 415 \\
\hline \multicolumn{5}{|l|}{ Cardiopteridaceae } \\
\hline Citronella paniculata (Mart.) R.A.Howard & $\mathrm{Av}$ & S-SE (CS) & $F A$ & LDM 505 \\
\hline \multicolumn{5}{|l|}{ Caryophyllaceae } \\
\hline Arenaria lanuginosa (Michx.) Rohrb. & $\mathrm{Ev}$ & America & $F A$ & LDM 316 \\
\hline Cerastium glomeratum Thuill. & Ev & America & $F A, A R, C A$ & LDM 644 \\
\hline Cerastium mollissimum Poir. & Ev & AmSul & $F A$ & LDM 639 \\
\hline Drymaria cordata (L.) Willd. ex Roem. \& Schult. & Ev & America & $F A$ & LDM 289 \\
\hline \multicolumn{5}{|l|}{ Celastraceae } \\
\hline Celastrus liebmanii Standl. & $\mathrm{Ab}$ & AmSul & $F A$ & LDM 786 \\
\hline Maytenus evonymoides Reissek & $\mathrm{Av}$ & S-SE-CO & $F A, A R$ & LDM 400 \\
\hline Maytenus glaucescens Reissek & $\mathrm{Ab}$ & S-SE-NE & $F A, A R$ & LDM 1046 \\
\hline \multicolumn{5}{|l|}{ Clethraceae } \\
\hline Clethra scabra Pers. & $\mathrm{Av}$ & AndNorte & $F A$ & LDM 321 \\
\hline \multicolumn{5}{|l|}{ Commelinaceae } \\
\hline Commelina obliqua Vahl & Ev & Neotrop. & $A F$ & LDM 797 \\
\hline
\end{tabular}




\begin{tabular}{|c|c|c|c|c|}
\hline Família/Espécie & Hábito & Distr. Geogr. & Fisionomia & No. coletor \\
\hline Commelina rufipes Seub. & Ev & Neotrop. & $F A$ & LDM 775 \\
\hline Tradescantia fluminensis Vell. & $\mathrm{Ev}$ & AmSul & $F A$ & LDM 616 \\
\hline Tripogandra diuretica (Mart.) Handlos & Ev & Neotrop. & $F A$ & LDM 774 \\
\hline \multicolumn{5}{|l|}{ Convolvulaceae } \\
\hline Cuscuta grandiflora Kunth & $\mathrm{Pt}$ & Neotrop. & $F A$ & LDM 629 \\
\hline Dichondra macrocalyx Meisn. & Ev & AmSul & $A R$ & LDM 1336 \\
\hline Ipomoea indivisa (Vell.) Hallier f. & $\mathrm{Ln}$ & S-SE (CS) & $F A$ & UEC 115808 \\
\hline Ipomoea purpurea (L.) Roth & Ln & AmSul & $F A$ & UEC 115809 \\
\hline \multicolumn{5}{|l|}{ Cucurbitaceae } \\
\hline Cyclanthera hystrix (Gill.) Arn. & $\mathrm{Ev}$ & Neotrop. & $A F$ & LDM 796 \\
\hline \multicolumn{5}{|l|}{ Cunoniaceae } \\
\hline Lamanonia ternata Vell. & $\mathrm{Av}$ & S-SE-NE-CO & $F A$ & LDM 375 \\
\hline Weinmannia organensis Gardner & Av & SE (ML) & $F A$ & LDM 1042 \\
\hline Weinmannia paulliniifolia Pohl ex Ser. & $\mathrm{Av}$ & S-SE & $F A$ & LDM 760 \\
\hline \multicolumn{5}{|l|}{ Cyperaceae } \\
\hline Bulbostylis capillaris (L.) C.B.Clarke & $\mathrm{Ev}$ & America & $A F$ & LDM 874 \\
\hline Bulbostylis consanguinea (Kunth) C.B.Clarke & Ev & S-SE-NE-CO (CS) & $A F$ & LDM 794 \\
\hline Bulbostylis juncoides (Vahl) Kük. & $\mathrm{Ev}$ & Neotrop. & $A F$ & LDM 301 \\
\hline Carex bonariensis Desf. ex Poir. & Ev & S-SE (CS) & $F A, C A$ & LDM 1190 \\
\hline Carex brasiliensis A.St.-Hil. & Ev & S-SE (CS) & $C A$ & LDM 1251 \\
\hline Carex polysticha Boeckeler & Ev & America & $C A$ & LDM 1232 \\
\hline Carex vesca C.B.Clarke & Ev & SE & $F A$ & LDM 872 \\
\hline Cryptangium triquetum Boeckeler & $\mathrm{Ev}$ & S-SE & $A F$ & LDM 312 \\
\hline Cyperus hermaphroditus (Jacq.) Standl. & $\mathrm{Ev}$ & Neotrop. & $A F$ & LSK 64/02 \\
\hline Cyperus luzulae (L.) Retz. & $\mathrm{Ev}$ & America & $A F$ & LDM 460 \\
\hline Eleocharis maculosa (Vahl) Roem \& Schult. & $\mathrm{Ev}$ & Neotrop. & $A F$ & LDM 1335 \\
\hline Pleurostachys orbignyana Brongn. & Ev & S-SE & $F A$ & LDM 1210 \\
\hline Pleurostachys stricta Kunth & Ev & S-SE & $F A$ & LDM 390 \\
\hline Pycreus lanceolatus (Poir.) C.B.Clarke & $\mathrm{Ev}$ & Neotrop. & $C A$ & WMF 1735 \\
\hline Pycreus cf. mundtii Ness & $\mathrm{Ev}$ & - & $C A$ & WMF 1734 \\
\hline Rhynchospora cf. berterii (Spreng.) C.B.Clarke & $\mathrm{Ev}$ & - & $A F$ & LDM 696 \\
\hline Rhynchospora corymbosa (L.) Britton & Ev & AMPLA & $A R$ & LDM 1058 \\
\hline Rhynchospora setigera Griseb. & Ev & S-SE-CO-NE (CS) & $C A$ & LDM 1229 \\
\hline Rhynchospora cf. subsetosa C.B.Clarke & Ev & - & $A F$ & LDM 306 \\
\hline Rhynchospora sp.1 & $\mathrm{Ev}$ & - & $C A$ & LDM 559 \\
\hline Rhynchospora sp. 2 & $\mathrm{Ev}$ & - & $C A$ & LDM3003 \\
\hline Uncinia hamata (Sw.) Urb. & Ev & Neotrop. & $F A$ & LDM 1209 \\
\hline \multicolumn{5}{|l|}{ Dioscoreaceae } \\
\hline Dioscorea campestris Griseb. & Ln & AmSul & $F A$ & LDM 845 \\
\hline \multicolumn{5}{|l|}{ Elaeocarpaceae } \\
\hline Sloanea hirsuta (Schott) Planch. ex Benth. & $\mathrm{Av}$ & S-SE-NE & $A R$ & $\mathrm{NCF}$ \\
\hline \multicolumn{5}{|l|}{ Ericaceae } \\
\hline Agarista chlorantha (Cham.) G.Don & $\mathrm{Ab}$ & S-SE-CO & $C A$ & LDM 750 \\
\hline Agarista oleifolia (Cham.) G.Don & $\mathrm{Ab}$ & S-SE-NE-CO & $A R$ & LDM 659 \\
\hline Gaultheria serrata (Vell.) Sleum. ex Kin.-Gouv. & $\mathrm{Ab}$ & S-SE (PS) & $A F$ & LDM 684 \\
\hline Gaylussacia amoena Cham. & $\mathrm{Ab}$ & S-SE (FA) & $C A$ & LDM 771 \\
\hline Gaylussacia chamissonis Meisn. & $\mathrm{Ab}$ & SE (ML) & $C A$ & LDM 702 \\
\hline Gaylussacia densa Meisn. & $\mathrm{Ab}$ & S-SE-NE & $F A, A F$ & LDM 710 \\
\hline Gaylussacia jordanensis Sleumer & $\mathrm{Ab}$ & SE (ML) & $C A$ & LDM 697 \\
\hline
\end{tabular}




\begin{tabular}{|c|c|c|c|c|}
\hline Família/Espécie & Hábito & Distr. Geogr. & Fisionomia & No. coletor \\
\hline Gaylussacia montana (Pohl) Sleumer & $\mathrm{Ab}$ & SE-NE & $A F$ & LDM 692 \\
\hline \multicolumn{5}{|l|}{ Eriocaulaceae } \\
\hline Paepalanthus caldensis Malme & Ev & S-SE (PS) & $C A$ & LDM 1175 \\
\hline Paepalanthus multicostatus Ruhland & Ev & $\mathrm{SE}(\mathrm{ML})$ & $C A$ & LDM 798 \\
\hline Paepalanthus planifolius (Bong.) Körn. & Ev & S-SE-NE-CO-N & $F A, A R, A F$ & LDM 563 \\
\hline Paepalanthus pseudotortilis Ruhland & Ev & SE (ML) & $A F$ & LDM 687 \\
\hline Paepalanthus usterii Beauv. & Ev & SE (ML) & $C A$ & LDM 391 \\
\hline \multicolumn{5}{|l|}{ Erythroxylaceae } \\
\hline Erythroxylum deciduum A.St.-Hil. & $\mathrm{Ab}$ & AndNorte & $A R, C A$ & LDM 1254 \\
\hline \multicolumn{5}{|l|}{ Escalloniaceae } \\
\hline Escallonia bifida Link \& Otto & $\mathrm{Av}$ & S-SE (CS) & $F A$ & LDM 0110 \\
\hline Escallonia farinacea A.St.-Hil. & $\mathrm{Ab}$ & S-SE (CS) & $C A$ & HLF 10679 \\
\hline \multicolumn{5}{|l|}{ Euphorbiaceae } \\
\hline Acalypha sp. & $\mathrm{Ev}$ & - & $A R$ & LDM 1328 \\
\hline Alchornea triplinervia Müll.Arg. & $\mathrm{Av}$ & Neotrop. & $F A$ & LDM 853 \\
\hline Croton dichrous Müll.Arg. & $\mathrm{Ab}$ & SE (ML) & $F A, A R, A F, C A$ & LDM 485 \\
\hline Croton erythroxyloides Baill. & $\mathrm{Ab}$ & SE-NE & $C A$ & LDM 558 \\
\hline Croton organensis Baill. & $\mathrm{Av}$ & SE-NE & $F A$ & LDM 1177 \\
\hline Croton piptocalyx Müll.Arg. & $\mathrm{Av}$ & SE-NE & $F A$ & LDM 490 \\
\hline Euphorbia portulacoides $\mathrm{L}$. & Ev & Andes & $A F$ & LDM 731 \\
\hline Euphorbia potentilloides Boiss. & $\mathrm{Ev}$ & S-SE-NE-CO & $C A$ & LDM 545 \\
\hline Sapium glandulosum (L.) Morong & $\mathrm{Av}$ & Neotrop. & $F A$ & LDM 725 \\
\hline \multicolumn{5}{|l|}{ Fabaceae } \\
\hline Camptosema scarlatinum (Benth.) Bukart & Ln & S-SE-NE-CO & $F A$ & LDM 633 \\
\hline Crotalaria breviflora DC. & $\mathrm{Ev}$ & S-SE-NE-CO & $C A$ & HLF 1847 \\
\hline Crotalaria miottoae A.S.Flores \& A.M.G.Azevedo & $\mathrm{Ab}$ & $\mathrm{SE}(\mathrm{CR})$ & $F A$ & LDM 024 \\
\hline Crotalaria paulina Schrank & Ev & Neotrop. & $C A$ & LDM 840 \\
\hline Dalbergia foliolosa Benth. & $\mathrm{Av}$ & S-SE-NE & $F A$ & LDM 1552 \\
\hline Dalbergia frutescens (Vell.) Britton & $\mathrm{Av}$ & Neotrop. & $A R$ & LDM 1222 \\
\hline Desmodium affine Schlecht. & Ev & AmSul & $C A$ & HLF 1852 \\
\hline Desmodium discolor Vogel & $\mathrm{Ab}$ & AmSul & $C A$ & LDM 973 \\
\hline Desmodium triarticulatum Malme & Ev & S-SE (CS) & $C A$ & LDM 994 \\
\hline Eriosema heterophyllum Benth. & Ev & S-SE-CO-N & $C A$ & LDM 540 \\
\hline Inga sessilis (Vell.) Mart. & $\mathrm{Av}$ & S-SE-NE-N & $F A$ & LDM 442 \\
\hline Lupinus paranensis C.P.Sm. & $\mathrm{Ab}$ & S-SE (PS) & $C A$ & LDM 1063 \\
\hline Machaerium villosum Vogel & $\mathrm{Av}$ & AmSul & $C A$ & ASF 624 \\
\hline Mimosa dolens Vell. & $\mathrm{Ab}$ & S-SE-CO & $C A$ & HLF 1856 \\
\hline Mimosa filipetiola Burkart & $\mathrm{Ab}$ & S-SE (FA) & $A F$ & LDM 018 \\
\hline Mimosa myriophylla Bong. ex Benth. & $\mathrm{Ab}$ & S-SE (PS) & $C A$ & HLF 1839 \\
\hline Mimosa ramosissima Benth. & $\mathrm{Ab}$ & S-SE (PS) & $C A$ & LDM 969 \\
\hline Mimosa scabrella Benth. & $\mathrm{Av}$ & S-SE (PS) & $A R$ & LDM 514 \\
\hline Senna splendida (Vogel) H.S.Irwin \& Barbeby & $\mathrm{Ab}$ & S-SE-NE-CO & $A R$ & $\begin{array}{c}\text { LSK 2012- } \\
04\end{array}$ \\
\hline Senna tropica (Vell.) H.S.Irwin \& Barneby & $\mathrm{Av}$ & S-SE (PS) & $F A, C A$ & LDM 789 \\
\hline Trifolium repens $\mathrm{L}$. & Ev & Ex & $F A$ & LDM593 \\
\hline Zornia reticulata $\mathrm{Sm}$. & Ev & Neotrop. & $C A$ & JLMAF 31 \\
\hline Zornia latifolia $\mathrm{Sm}$. & Ev & Neotrop. & $C A$ & JLMAF 40 \\
\hline \multicolumn{5}{|l|}{ Gentianaceae } \\
\hline Calolisianthus pedunculatus (Cham. \& Schltdl.) Gilg & Ev & S-SE-NE-CO & $C A$ & LDM 996 \\
\hline
\end{tabular}




\begin{tabular}{|c|c|c|c|c|}
\hline Família/Espécie & Hábito & Distr. Geogr. & Fisionomia & No. coletor \\
\hline \multicolumn{5}{|l|}{ Gesneriaceae } \\
\hline Sinningia allagophylla (Mart.) Wiehler & Ev & S-SE-CO & $C A$ & LDM 751 \\
\hline Sinningia douglasii (Lindl.) Chautems & Ep & S-SE & $A R$ & LDM 660 \\
\hline Sinningia gigantifolia Chautems & Ev & SE (ML) & $F A$ & LDM 780 \\
\hline Sinningia magnifica (Otto \& Dietr.) Wiehler & Ev & SE (ML) & $A F$ & LDM 012 \\
\hline \multicolumn{5}{|l|}{ Griseliniaceae } \\
\hline Griselinia ruscifolia (Clos) Taub. & $\mathrm{Pt}$ & AndSul & $F A$ & LDM 314 \\
\hline \multicolumn{5}{|l|}{ Hypericaceae } \\
\hline Hypericum brasiliense Choisy & $\mathrm{Ab}$ & AndNorte & $F A, A F, C A$ & LDM 313 \\
\hline \multicolumn{5}{|l|}{ Hypoxidaceae } \\
\hline Hypoxis decumbens $\mathrm{L}$. & Ev & Neotrop. & $A F$ & LDM 894 \\
\hline \multicolumn{5}{|l|}{ Iridaceae } \\
\hline Calydorea campestris (Klatt) Baker & $\mathrm{Ev}$ & S-SE (CS) & $F A, C A$ & LDM 753 \\
\hline Neomarica caerulea (Ker Gawl.) Sprague & Ev & S-SE (CS) & $C A$ & LDM 1841 \\
\hline Sisyrinchium commutatum Klatt & Ev & S-SE-NE-CO & $C A$ & LDM 1235 \\
\hline Sisyrinchium micranthum Cav. & Ev & Neotrop. & $C A$ & LDM 1242 \\
\hline Sisyrinchium palmifolium $\mathrm{L}$. & Ev & AmSul & $C A$ & LDM 1034 \\
\hline Sisyrinchium vaginatum Spreng. & Ev & AmSul & $F A, A F, C A$ & LDM 406 \\
\hline Trimezia spathata (Klatt) Baker subesp. spathata & Ev & S-SE-NE-CO & $C A$ & LDM 752 \\
\hline \multicolumn{5}{|l|}{ Juncaceae } \\
\hline Juncus effusus L. & Ev & America & $F A$ & LDM 850 \\
\hline Juncus microcephalus Kunth & Ev & Neotrop. & $A F$ & LDM 893 \\
\hline Juncus tenuis Willd. & Ev & America & $A F$ & LDM 302 \\
\hline Luzula ulei Buchenau & Ev & S-SE (FA) & $F A, A F$ & LDM 585 \\
\hline \multicolumn{5}{|l|}{ Lamiaceae } \\
\hline Aegiphila obducta Vell. & $\mathrm{Av}$ & S-SE (PS) & $A R$ & LDM 1072 \\
\hline Cunila galioides Benth. & Ev & S-SE (PS) & $A F$ & LDM 946 \\
\hline Eriope crassipes Benth. & Ev & AmSul & $C A$ & LDM 544 \\
\hline Hyptis propinqua Epling. & $\mathrm{Ab}$ & SE (MM) & $F A$ & LDM 1039 \\
\hline Ocimum carnosum (Spreng.) Link \& Otto ex Benth. & Ev & Ex & $F A$ & LDM 967 \\
\hline Prunella vulgaris $\mathrm{L}$. & Ev & Ex & $F A$ & LDM 019 \\
\hline Salvia arenaria A.St.-Hil. ex Benth. & $\mathrm{Ab}$ & SE (ML) & $F A$ & LDM 428 \\
\hline Salvia campos-portoi Dusén & $\mathrm{Ab}$ & SE (MM) & $F A$ & LDM 646 \\
\hline Salvia confertiflora Pohl & $\mathrm{Ab}$ & SE (ML) & $F A$ & HLF 1820 \\
\hline Salvia sellowiana Benth. & $\mathrm{Ab}$ & SE (MM) & $F A$ & LDM 562 \\
\hline \multicolumn{5}{|l|}{ Lauraceae } \\
\hline Nectandra barbellata Coe-Teix. & Av & SE (ML) & $F A, A R$ & LDM 666 \\
\hline Nectandra grandiflora Ness & $\mathrm{Av}$ & S-SE-CO & $F A$ & LDM 519 \\
\hline Nectandra nitidula Ness & Av & S-SE-NE & $F A$ & LDM 502 \\
\hline Ocotea nutans $\mathrm{Mez}$ & $\mathrm{Av}$ & S-SE-NE & $F A$ & LDM 591 \\
\hline Ocotea porosa (Nees \& C.Mart.) Barroso & $\mathrm{Av}$ & S-SE (CS) & $F A$ & LDM 454 \\
\hline Ocotea puberula Nees & $\mathrm{Av}$ & Neotrop. & $F A, A R$ & LDM 356 \\
\hline Ocotea vaccinioides Mez & Av & S-SE & $F A$ & NCF \\
\hline Ocotea virgultosa (Ness) Mart. ex Mez & $\mathrm{Av}$ & $\mathrm{SE}(\mathrm{CJ})$ & $F A$ & LDM 580 \\
\hline Persea willdenovii Kosterm. & $\mathrm{Av}$ & S-SE-NE-CO & $F A$ & $\mathrm{NCF}$ \\
\hline \multicolumn{5}{|l|}{ Lentibulariaceae } \\
\hline Utricularia reniformis A.St.-Hil. & $\mathrm{Ev}$ & S-SE (FA) & $A F$ & LDM 649 \\
\hline \multicolumn{5}{|l|}{ Loganiaceae } \\
\hline Strychnos brasiliensis Mart. & $\mathrm{Ab}$ & S-SE-NE-CO & $F A, A R$ & LDM 1221 \\
\hline
\end{tabular}




\begin{tabular}{|c|c|c|c|c|}
\hline Família/Espécie & Hábito & Distr. Geogr. & Fisionomia & No. coletor \\
\hline Spigelia tetraptera Taub. & Ev & S-SE & $F A$ & LDM 009 \\
\hline \multicolumn{5}{|l|}{ Loranthaceae } \\
\hline Struthanthus frexicaulis (Mart.) Mart. & $\mathrm{Pt}$ & S-SE-NE-CO & $F A$ & LDM 370 \\
\hline \multicolumn{5}{|l|}{ Lythraceae } \\
\hline Cuphea glutinosa Cham. \& Schltdl. & $\mathrm{Ab}$ & S-SE-NE & $F A, A F$ & LDM 016 \\
\hline Cuphea ingrata Cham. \& Schltdl. & $\mathrm{Ab}$ & S-SE (CS) & $\begin{array}{c}F A, A R \\
C A\end{array}$ & LDM 987 \\
\hline Cuphea racemosa (L.f.) Spreng. & $\mathrm{Ab}$ & Neotrop. & $C A$ & LDM 988 \\
\hline Lafoensia $\mathrm{sp}$. & $\mathrm{Ab}$ & - & $C A$ & LDM 3380 \\
\hline \multicolumn{5}{|l|}{ Malpighiaceae } \\
\hline Byrsonima cf. ligustrifolia A.St.-Hil. & $\mathrm{Av}$ & - & $F A$ & LDM 1253 \\
\hline Byrsonima variabilis A.Juss. & $\mathrm{Ab}$ & SE-NE & $C A$ & LDM 700 \\
\hline Heteropterys intermedia (Griseb.) A.Juss. & Ln & S-SE-NE & $F A$ & LDM 1024 \\
\hline Heteropterys sp. & Ln & - & $F A$ & $\begin{array}{c}\text { LSK } \\
16 / 2012\end{array}$ \\
\hline \multicolumn{5}{|l|}{ Malvaceae } \\
\hline Abutilon bedfordianum (Hook.) A.St.-Hil. \& Naudin & $\mathrm{Av}$ & $\mathrm{SE}(\mathrm{CR})$ & $F A$ & LDM 388 \\
\hline Abutilon itatiaiae R.E.Fr. & $\mathrm{Ab}$ & SE (MM) & $F A$ & LDM 013 \\
\hline Abutilon macranthum A.St.-Hil. & $\mathrm{Av}$ & $\mathrm{SE}(\mathrm{CR})$ & & LDM 1026 \\
\hline Abutilon regnelli Miq. & $\mathrm{Ab}$ & SE (ML) & $F A$ & UEC 64.897 \\
\hline Krapovickasia macrodon (A.DC.) Fryxell & Ev & S-SE-CO & $C A$ & LDM 547 \\
\hline Pavonia kleinii Krap. \& Crist. & $\mathrm{Ab}$ & S-SE & $C A$ & LDM 1248 \\
\hline Triumfetta semitriloba Jacq. & $\mathrm{Ab}$ & America & $A R$ & LDM 1036 \\
\hline Sida rhombifolia $\mathrm{L}$. & $\mathrm{Ab}$ & America & $C A$ & LDM 1035 \\
\hline \multicolumn{5}{|l|}{ Melastomataceae } \\
\hline $\begin{array}{l}\text { Cambessedesia espora subesp. ilicifolia (DC.) } \\
\text { A.B.Martins }\end{array}$ & $\mathrm{Ab}$ & S-SE-CO & $C A$ & LDM 548 \\
\hline Leandra aurea (Cham.) Cogn. & $\mathrm{Ab}$ & S-SE-NE & $C A$ & LDM 554 \\
\hline Leandra barbinervis (Cham. ex Triana) Cogn. & $\mathrm{Av}$ & S-SE (PS) & $F A$ & LDM 380 \\
\hline Leandra carassana (DC.) Cogn. & Av & S-SE-NE & $F A$ & LDM 029 \\
\hline Leandra cordigera Cogn. & $\mathrm{Ab}$ & S-SE (PS) & $A R$ & LDM 809 \\
\hline Leandra gynoverrucosa Reginato & $\mathrm{Ab}$ & SE (MM) & $F A$ & LDM 483 \\
\hline Leandra hirtella Cogn. & $\mathrm{Ab}$ & S-SE (PS) & $A R$ & LDM 810 \\
\hline Leandra multiplinervis (Naudin) Cogn. & $\mathrm{Ab}$ & Neotrop. & $F A$ & LDM 856 \\
\hline Leandra quinquedentata (Mart. \& Schr.) Cogn. & $\mathrm{Ab}$ & S-SE-NE & $F A$ & LDM 847 \\
\hline Leandra regnellii (Triana) Cogn. & $\mathrm{Ab}$ & S-SE (PS) & $F A$ & LDM 855 \\
\hline Leandra sulfurea (Naudin) Cogn. & $\mathrm{Ab}$ & S-SE (PS) & $F A, A F$ & LDM 010 \\
\hline Miconia cinerascens Miq. & $\mathrm{Av}$ & S-SE-CO (CS) & $F A$ & LDM 359 \\
\hline Miconia pusilliflora (DC.) Naudin & $\mathrm{Av}$ & S-SE-NE (CS) & $F A$ & LDM 1076 \\
\hline Miconia sellowiana Naudin & $\mathrm{Av}$ & S-SE-CO & $F A$ & LDM 722 \\
\hline Microlepis oleifolia Triana & $\mathrm{Ab}$ & S-SE (FA) & $A F$ & LDM 885 \\
\hline Rhynchanthera brachyrhyncha Cham. & $\mathrm{Ev}$ & S-SE (CS) & $A F$ & LDM 838 \\
\hline Tibouchina cerastifolia Cogn. & $\mathrm{Ab}$ & S-SE-CO & $A F$ & LDM 952 \\
\hline Tibouchina fothergillae (Sch. et Mart. ex DC.) Cogn. & $\mathrm{Av}$ & $\mathrm{SE}(\mathrm{CR})$ & $F A$ & LDM 960 \\
\hline Tibouchina foveolata (Naudin) Cogn. & $\mathrm{Ab}$ & $\mathrm{SE}(\mathrm{CR})$ & $F A, A F, C A$ & LDM 028 \\
\hline Tibouchina frigidula (DC.) Cogn. & $\mathrm{Ab}$ & S-SE (PS) & $C A$ & LDM 887 \\
\hline Tibouchina hospita Cogn. & Ev & SE (ML) & $A F$ & LDM 708 \\
\hline Tibouchina martialis (Cham.) Cogn. & $\mathrm{Ab}$ & S-SE-CO & $A F$ & LDM 701 \\
\hline Tibouchina mosenii Cogn. & $\mathrm{Ab}$ & SE (ML) & $A F, C A$ & LDM 781 \\
\hline
\end{tabular}




\begin{tabular}{|c|c|c|c|c|}
\hline Família/Espécie & Hábito & Distr. Geogr. & Fisionomia & No. coletor \\
\hline Tibouchina sellowiana Cogn. & $\mathrm{Av}$ & S-SE & $F A$ & LDM 836 \\
\hline Trembleya phlogiformis DC. & $\mathrm{Ab}$ & SE-NE-CO-N & $A F$ & LDM 839 \\
\hline \multicolumn{5}{|l|}{ Meliaceae } \\
\hline Cabralea canjerana (Vell.) Mart. & $\mathrm{Av}$ & AmSul & $F A$ & LDM379 \\
\hline \multicolumn{5}{|l|}{ Menispermaceae } \\
\hline Cissampelos sp. & $\mathrm{Ln}$ & - & $F A$ & LDM 3384 \\
\hline \multicolumn{5}{|l|}{ Monimiaceae } \\
\hline Macropeplus dentatus (Perkins) I.Santos \& Peixoto & $\mathrm{Av}$ & SE (ML) & $F A$ & LDM 955 \\
\hline Mollinedia clavigera Tull. & Av & S-SE (PS) & $F A, A R$ & LDM 401 \\
\hline \multicolumn{5}{|l|}{ Myrtaceae } \\
\hline Calyptranthes cf. brasiliensis Spreng & $\mathrm{Av}$ & - & $F A$ & LDM 466 \\
\hline Calyptranthes grandifolia O.Berg. & Av & S-SE & $F A, A R$ & LDM 745 \\
\hline Campomanesia pubescens (DC.) O.Berg & $\mathrm{Ab}$ & S-SE-NE-CO & $C A$ & LDM 546 \\
\hline Campomanesia simulans M.L.Kawas. & $\mathrm{Av}$ & S-SE & $C A$ & HLF 1867 \\
\hline Eugenia involucrata DC. & Av & S-SE & $F A$ & LDM 764 \\
\hline Eugenia sp. & $\mathrm{Av}$ & - & $F A$ & $\mathrm{NCF}$ \\
\hline $\begin{array}{l}\text { Myrceugenia brevipedicellata (Burret) D.Legrand \& } \\
\text { Kausel }\end{array}$ & $\mathrm{Ab}$ & $\mathrm{SE}(\mathrm{CJ})$ & $C A$ & LSK 137/02 \\
\hline Myrceugenia cucculatta D.Legrand & $\mathrm{Av}$ & S-SE (PS) & $F A$ & LDM 463 \\
\hline Myrceugenia hoehnei (Burret) D.Legrand \& Kausel & Av & S-SE (PS) & $F A$ & LDM 681 \\
\hline Myrceugenia miersiana (Gardner) D.Legrand \& Kausel & Av & S-SE-NE & $A R$ & LDM 1150 \\
\hline Myrceugenia myrcioides (Camb.) O.Berg & $\mathrm{Av}$ & S-SE (PS) & $F A$ & LDM 377 \\
\hline Myrceugenia ovalifolia (O.Berg) Landrum & Av & S-SE (PS) & $F A$ & LDM 386 \\
\hline $\begin{array}{l}\text { Myrcengenia regnelliana (O.Berg) D.Legrand \& } \\
\text { Kausel }\end{array}$ & $\mathrm{Av}$ & S-SE & $F A$ & LDM 435 \\
\hline Myrceugenia rufescens (DC.) D.Legrand \& Kausel & Av & S-SE (PS) & $F A$ & LDM 831 \\
\hline Myrceugenia scutellata D.Legrand & Av & S-SE (PS) & $F A$ & LDM 609 \\
\hline Myrcia guianensis (Aubl.) DC. & Av & Neotrop. & $F A, A R$ & LDM 504 \\
\hline Myrcia hartwegiana (O.Berg) Kiaersk. & $\mathrm{Ab}$ & S-SE (PS) & $C A$ & LSK $121 / 02$ \\
\hline Myrcia laruotteana Cambess. & Av & S-SE-NE-CO-N & $F A, A R$ & LDM 678 \\
\hline Myrcia retorta Cambess. & $\mathrm{Av}$ & S-SE & $F A, A R$ & LDM 630 \\
\hline Myrcia splendens (Sw.) DC. & Av & Neotrop. & $F A, A R$ & LDM 717 \\
\hline Myrcia venulosa DC. & Av & S-SE-NE & $A R$ & LDM 826 \\
\hline Myrcia sp. & $\mathrm{Av}$ & - & $F A$ & LDM 575 \\
\hline Pimenta pseudocaryophyllus (Gomes) Landrum & Av & S-SE (PS) & $F A$ & LDM 357 \\
\hline Psidium rufum DC. & $\mathrm{Av}$ & S-SE-NE-CO-N & $A R$ & LDM 560 \\
\hline Siphoneugena dussii (Krug et Urb.) C.Proença & $\mathrm{Av}$ & S-SE-NE-CO-N & $F A$ & LDM 599 \\
\hline \multicolumn{5}{|l|}{ Oleaceae } \\
\hline Ligustrum sinense Lour. & Av & Ex & $A R$ & LDM 820 \\
\hline \multicolumn{5}{|l|}{ Onagraceae } \\
\hline Fuchsia regia (Vell.) Munz & $\mathrm{Ab}$ & S-SE-NE & $F A, A R, A F, C A$ & LDM 015 \\
\hline Ludwigia elegans (Cambess.) H.Hara & $\mathrm{Ab}$ & AmSul & $F A, C A$ & LDM 857 \\
\hline \multicolumn{5}{|l|}{ Orchidaceae } \\
\hline Alatiglossum cogniauxianum (Schltr.) Baptista & Ep & S-SE (PS) & $A R$ & LDM 974 \\
\hline Brasiliorchis picta (Hook.) R.B.Singer et al. & Ep & S-SE (PS) & $A R, A F$ & LDM 403 \\
\hline Coppensia loefgrenii (Cogn.) F.Barros \& V.T.Rodrigues & Ep & S-SE-NE & $F A$ & LDM 1037 \\
\hline $\begin{array}{l}\text { Coppensia longicorna (Mutel) F.Barros \& } \\
\text { V.T.Rodrigues }\end{array}$ & Ep & S-SE (PS) & $A R$ & LDM 754 \\
\hline Coppensia welteri (Pabst) Campacii & Ep & SE (ML) & $F A$ & LDM 833 \\
\hline
\end{tabular}




\begin{tabular}{|c|c|c|c|c|}
\hline Família/Espécie & Hábito & Distr. Geogr. & Fisionomia & No. coletor \\
\hline Coppensia sp. & $\mathrm{Ev}$ & - & $A F$ & LDM 027 \\
\hline Cyclopogon sp.1 & Ev & - & $F A$ & LDM 478 \\
\hline Cyclopogon sp.2 & Ev & - & $F A$ & LDM 844 \\
\hline Cranichis candida (Barb.Rodr.) Cogn. & Ev & S-SE-CO & $F A$ & LDM 285 \\
\hline Govenia utriculata (Sw.) Lindl. & Ev & S-SE-CO & $F A$ & LDM 842 \\
\hline Habenaria secunda Lindl. & Ev & S-SE-CO & $F A$ & LDM 864 \\
\hline Habenaria cf. longicauda Hook. & Ev & - & $A F$ & LDM 971 \\
\hline Habenaria sp.1 & $\mathrm{Ev}$ & - & $A F$ & LDM 890 \\
\hline Habenaria $\mathrm{sp} .2$ & Ev & - & $A F$ & LDM 895 \\
\hline Hadrolaelia coccinea (Lindl.) Chiron \& V.P.Castro & Ep & S-SE-NE-CO & $F A$ & LDM 464 \\
\hline Hapalorchis micranthus (Barb.Rodr.) Hoehne & Ev & S-SE (FA) & $F A$ & LDM 284 \\
\hline Malaxis parthonii C.Morren & Ev & S-SE-NE & $F A$ & LDM 714 \\
\hline Octomeria sp. & Ev & - & $A F$ & LDM 694 \\
\hline Pelexia oestrifera (Rchb.f \& Warm.) Schltr. & $\mathrm{Ev}$ & S-SE-NE-CO & $A F$ & LDM 005 \\
\hline Phymatidium cf. deliculatum Lindl. & Ep & - & $A R$ & LDM 3375 \\
\hline Pleurothallis sp.1 & Ep & - & $A R$ & LDM 1214 \\
\hline Pleurothallis sp.2 & Ep & - & $A R$ & LSK $85 / 02$ \\
\hline Prescottia stachyodes (Sw.) Lindl. & Ev & S-SE-NE-CO-N & $F A$ & LDM 1083 \\
\hline Sacoila lanceolata (Aubl.) Garay & Ev & Neotrop. & $C A$ & LDM 625 \\
\hline Zygopetalum sp. & Ev & - & $A F$ & LSK $107 / 02$ \\
\hline \multicolumn{5}{|l|}{ Orobanchaceae } \\
\hline Velloziella dracocephaloides Baill. & Ev & SE (ML) & $F A$ & LDM 673 \\
\hline \multicolumn{5}{|l|}{ Oxalidaceae } \\
\hline Oxalis corniculata $\mathrm{L}$. & Ev & Ex & $F A$ & LDM 784 \\
\hline Oxalis confertissima A.St.-Hil. & $\mathrm{Ev}$ & S-SE (FA) & $C A$ & LDM 1260 \\
\hline Oxalis rupestris A.St.-Hil. & Ev & S-SE (CS) & $A F$ & LDM 648 \\
\hline \multicolumn{5}{|l|}{ Passifloraceae } \\
\hline Passiflora amethystina J.C.Mikan & $\mathrm{Ln}$ & S-SE-NE-CO & $F A$ & LDM 020 \\
\hline Passiflora edulis Sims & Ln & S-SE-NE-CO-N & $F A$ & LDM 664 \\
\hline Passiflora mendoncaei Harms & Ln & S-SE (PS) & $F A$ & LDM 665 \\
\hline \multicolumn{5}{|l|}{ Pentaphylacaceae } \\
\hline Ternstroemia cuneifolia Gardner & $\mathrm{Ab}$ & $\mathrm{SE}(\mathrm{CR})$ & $F A$ & LDM 1307 \\
\hline \multicolumn{5}{|l|}{ Phyllanthaceae } \\
\hline Phyllanthus niruri L. & $\mathrm{Ab}$ & America & $F A$ & LDM 953 \\
\hline \multicolumn{5}{|l|}{ Phytolaccaceae } \\
\hline Phytolacca thyrsiflora Fenzl. ex J.A.Schmidt & $\mathrm{Ab}$ & Neotrop. & $F A$ & LDM 614 \\
\hline \multicolumn{5}{|l|}{ Piperaceae } \\
\hline Peperomia augescens Miq. & Ep & S-SE-NE & $F A$ & LDM 512 \\
\hline Peperomia castelosensis Yunck. & Ep & S-SE (PS) & $F A$ & LDM 424 \\
\hline Peperomia galioides Kunth & $\mathrm{Ev}$ & Neotrop. & $F A, A F$ & LDM 014 \\
\hline Peperomia hilariana Miq. & Ep & S-SE (PS) & $F A$ & LDM 846 \\
\hline Peperomia hispidula (Sw.) A.Dietr. & Ep & Neotrop. & $F A, A R$ & LDM 859 \\
\hline Peperomia subternifolia Yunck. & Ep & SE (MM) & $F A$ & LDM 381 \\
\hline Piper gaudichaudianum Kunth & $\mathrm{Ab}$ & S-SE-NE & $F A$ & LDM 404 \\
\hline Piper regnellii (Miq.) C.DC. & $\mathrm{Ab}$ & Neotrop. & $F A$ & LDM 1078 \\
\hline \multicolumn{5}{|l|}{ Plantaginaceae } \\
\hline Mecardonia procumbens (Mill.) Small & $\mathrm{Ev}$ & Neotrop. & $A F, C A$ & LDM 732 \\
\hline Plantago guilleminiana Decne. & $\mathrm{Ev}$ & S-SE (PS) & $F A, C A$ & LDM 645 \\
\hline Plantago tomentosa Lam. & Ev & AndNorte & $F A, A R$ & LDM 662 \\
\hline
\end{tabular}




\begin{tabular}{|c|c|c|c|c|}
\hline Família/Espécie & Hábito & Distr. Geogr. & Fisionomia & No. coletor \\
\hline Veronica arvensis $\mathrm{L}$. & Ev & America & $F A, A F$ & LDM 683 \\
\hline \multicolumn{5}{|l|}{ Poaceae } \\
\hline Agrostis pellitus (Nees ex Trin.) Hitch. \& Chase & Ev & S-SE (CS) & $A F$ & LDM 325 \\
\hline Axonopus siccus (Nees) Kuhlm. & $\mathrm{Ev}$ & Andes & $A F$ & LDM 870 \\
\hline $\begin{array}{l}\text { Chascolytrum calotheca (Trin.) Essi, Longi-Wagner } \\
\text { \& Souza-Chies. }\end{array}$ & $\mathrm{Ev}$ & S-SE (CS) & $A F$ & LDM 655 \\
\hline Chusquea aff. meyeriana Rupr. ex Döll & $\mathrm{Bb}$ & - & $F A$ & LDM 1020 \\
\hline Chusquea leptophylla Nees & $\mathrm{Bb}$ & S-SE (FA) & $F A$ & LDM 1181 \\
\hline Digitaria insularis (L.) Sedde & Ev & Ex & $C A$ & LDM 556 \\
\hline Ichnanthus pallens (Swartz) Munro ex Bentham & Ev & America & $F A$ & LDM 966 \\
\hline Panicum sp. & Ev & - & $A F$ & LDM 891 \\
\hline Paspalum sp. & Ev & - & $C A$ & LDM 1334 \\
\hline Poа аппиа $\mathrm{L}$. & Ev & Ex & $F A$ & LDM 291 \\
\hline Pseudechinolaena polystachya (Kunth) Standl. & $\mathrm{Ev}$ & America & $F A$ & LDM 1306 \\
\hline \multicolumn{5}{|l|}{ Podocarpaceae } \\
\hline Podocarpus lambertii Klotzsch ex Endl. & $\mathrm{Av}$ & S-SE-NE & $F A, A R$ & LDM 530 \\
\hline \multicolumn{5}{|l|}{ Polemoniaceae } \\
\hline Cobaea scandens Cav. & Ln & Ex & $F A$ & LDM 977 \\
\hline \multicolumn{5}{|l|}{ Polygalaceae } \\
\hline Caamembeca insignis (Chodat.) J.F.B.Pastore & Ev & S-SE-NE & $F A, A R, A F, C A$ & LDM 031 \\
\hline Polygala campestris Gardner & $\mathrm{Ev}$ & S-SE (PS) & $A F$ & LDM 688 \\
\hline Polygala cneorum A.St.-Hil. & Ev & S-SE (PS) & $A F$ & LDM 300 \\
\hline Polygala lancifolia A.St.-Hil. \& Moq. & Ev & S-SE-CO (CS) & $F A, A F$ & LDM 332 \\
\hline Polygala pulchella A.St.-Hil. \& Moq. & $\mathrm{Ev}$ & S-SE (CS) & $A F, C A$ & LDM 976 \\
\hline \multicolumn{5}{|l|}{ Polygonaceae } \\
\hline Polygonum acuminatum Kunth & Ev & Neotrop. & $F A, A R, C A$ & LDM 283 \\
\hline Polygonum capitatum Ham. ex D.Don & Ev & Ex & $A F$ & LDM 521 \\
\hline Polygonum hydropiperoides Michx. & Ev & America & $C A$ & WMF 1736 \\
\hline Polygonum punctatum Elliott & Ev & Neotrop. & $C A$ & LDM 995 \\
\hline \multicolumn{5}{|l|}{ Primulaceae } \\
\hline $\begin{array}{l}\text { Lysimachia filiformis (Cham. \& Schltdl.) U.Manns } \\
\text { \& Anderb. }\end{array}$ & Ev & Neotrop. & $A F$ & LDM 001 \\
\hline Myrsine coriacea (Sw.) R.Br. ex Roem. \& Schult. & $\mathrm{Ab}$ & Neotrop. & $C A$ & LDM 1226 \\
\hline Myrsine gardneriana A.DC. & Av & S-SE-NE & $F A$ & LDM 487 \\
\hline Myrsine lineata (Mez) Imkhan. & $\mathrm{Ab}$ & S-SE-CO & $F A, A R$ & LDM 757 \\
\hline Myrsine umbellata Mart. & $\mathrm{Av}$ & S-SE-NE & $F A, A R$ & LDM 342 \\
\hline \multicolumn{5}{|l|}{ Proteaceae } \\
\hline Euplassa itatiaiae Sleumer & $\mathrm{Av}$ & SE (MM) & $F A$ & LDM 761 \\
\hline Roupala rhombifolia Mart. ex Meisn. & Av & S-SE-NE & $F A$ & LDM 456 \\
\hline \multicolumn{5}{|l|}{ Ranunculaceae } \\
\hline Anemone sellowii Pritz. & $\mathrm{Ev}$ & S-SE (FA) & $F A$ & LDM 295 \\
\hline Clematis dioica $\mathrm{L}$. & Ln & Neotrop. & $F A$ & LDM 287 \\
\hline Ranunculus flagelliformis $\mathrm{Sm}$. & Ev & Neotrop. & $A R, C A$ & LDM 1196 \\
\hline Ranunculus repens $\mathrm{L}$. & Ev & America & $C A$ & LDM 025 \\
\hline \multicolumn{5}{|l|}{ Rhamnaceae } \\
\hline Rhamnus sphaerosperma Sw. & $\mathrm{Av}$ & AndNorte & $F A, A R$ & LDM 790 \\
\hline \multicolumn{5}{|l|}{ Rosaceae } \\
\hline Fragaria vesca $\mathrm{L}$. & Ev & America & $F A$ & LDM 587 \\
\hline Prunus myrtifolia (L.) Urb. & $\mathrm{Av}$ & Neotrop. & $F A$ & LDM 1050 \\
\hline
\end{tabular}




\begin{tabular}{|c|c|c|c|c|}
\hline Família/Espécie & Hábito & Distr. Geogr. & Fisionomia & No. coletor \\
\hline Rubus erythroclados Mart. & $\mathrm{Ab}$ & S-SE (PS) & $F A$ & LDM 468 \\
\hline \multicolumn{5}{|l|}{ Rubiaceae } \\
\hline Borreria verticillata (L.) G.F.V.Meyers & $\mathrm{Ab}$ & Neotrop. & $A F$ & LDM 804 \\
\hline Coccocypselum condalia Pers. & Ev & AndNorte & $F A$ & LDM 004 \\
\hline Coccocypselum lymansmithii Standl. & Ev & S-SE (FA) & $A R$ & LDM 1329 \\
\hline $\begin{array}{l}\text { Declieuxia cordigera Mart. \& Zucc. ex Schult. \& } \\
\text { Schult.f. }\end{array}$ & Ev & S-SE-NE-CO & $C A$ & LDM 703 \\
\hline Diodia sp. & Ev & - & $F A, A F$ & LDM 773 \\
\hline Galianthe vaginata E.L.Cabral \& Bacigalupo & Ev & $\mathrm{SE}(\mathrm{ML})$ & $F A, A F$ & LDM 608 \\
\hline Galianthe valerianoides (Cham. \& Schltdl.) E.L.Cabral & Ev & S-SE-CO (CS) & $A F$ & LDM 803 \\
\hline Galium hypocarpium (L.) Endl. ex Griseb. & Ev & AndNorte & $F A$ & LSK 90/02 \\
\hline Galium noxium (A.St.-Hil.) Dempster & Ev & AndNorte & $F A$ & LDM 331 \\
\hline Manettia congesta (Vell.) K. Schum. & Ln & SE (CJ) & $F A$ & $\begin{array}{c}\text { LSK } \\
18 / 2012\end{array}$ \\
\hline Manettia luteo-rubra (Vell.) Benth. & $\mathrm{Ln}$ & S-SE-CO & $A R$ & LDM 972 \\
\hline Mitracarpus sp. & Ev & - & $A F$ & LDM 877 \\
\hline Palicourea rudgeoides (Müll.Arg.) Standl. & $\mathrm{Ab}$ & SE (ML) & $A R$ & LDM 851 \\
\hline Psychotria vellosiana Benth. & Av & Neotrop. & $F A, A R$ & LDM 339 \\
\hline Psychotria stachyoides Benth. & $\mathrm{Ab}$ & S-SE (FA) & $F A$ & LDM 674 \\
\hline Psychotria suterella Müll.Arg. & $\mathrm{Ab}$ & S-SE & $F A$ & LDM 414 \\
\hline Richardia stellaris (Cham. \& Schltdl.) Steud. & Ev & S-SE-CO (CS) & $C A$ & LDM 3387 \\
\hline Richardia sp. & Ev & - & $A F$ & LDM 896 \\
\hline Rudgea jasminoides (Cham.) Müll.Arg. & $\mathrm{Ab}$ & S-SE (CS) & $F A, A R$ & LDM 748 \\
\hline \multicolumn{5}{|l|}{ Rutaceae } \\
\hline Zanthoxylum rhoifolium Lam. & $\mathrm{Av}$ & AmSul & $A R$ & $\mathrm{NCF}$ \\
\hline \multicolumn{5}{|l|}{ Sabiaceae } \\
\hline Meliosma sellowii Urb. & Av & S-SE-NE & $F A$ & LDM 1061 \\
\hline \multicolumn{5}{|l|}{ Salicaceae } \\
\hline Abatia glabra Sleumer & $\mathrm{Ab}$ & SE (MM) & $F A$ & LDM 802 \\
\hline Azara uruguayensis (Speg.) Sleumer & Av & S-SE (CS) & $A R$ & LDM 531 \\
\hline Casearia decandra Jacq. & Av & Neotrop. & $F A$ & LDM 1553 \\
\hline Xylosma ciliatifolia (Clos) Eichler & $\mathrm{Av}$ & AndNorte & $F A$ & LDM 374 \\
\hline \multicolumn{5}{|l|}{ Sapindaceae } \\
\hline Allophylus cf. guaraniticus (A.St.-Hil.) Radlk. & Av & - & $A R$ & LDM 3374 \\
\hline Cupania zanthoxyloides Cambess. & Av & $\mathrm{SE}(\mathrm{ML})$ & $F A$ & LDM 288 \\
\hline Paullinia carpopoda Cambess. & $\mathrm{Ln}$ & S-SE-NE & $F A$ & LDM 1163 \\
\hline Serjania cf. gracilis Radlk. & $\mathrm{Ln}$ & - & $F A$ & LDM 975 \\
\hline \multicolumn{5}{|l|}{ Sapotaceae } \\
\hline $\begin{array}{l}\text { Chrysophyllum marginatum (Hook. \& Arn.) Radlk } \\
\text { Scrophulariaceae }\end{array}$ & Av & Neotrop. & $F A$ & $\mathrm{NCF}$ \\
\hline \multicolumn{4}{|l|}{ Smilacaceae } & LDM 429 \\
\hline Smilax brasiliensis Spreng. & Ln & SE-CO & $F A$ & LDM 448 \\
\hline Smilax elastica Griseb. & Ln & S-SE-NE-CO & $F A$ & LDM 1023 \\
\hline \multicolumn{5}{|l|}{ Solanaceae } \\
\hline Aureliana fasciculata (Vell.) Sendtn. & Av & S-SE-NE & $F A$ & LDM 355 \\
\hline Browallia americana $\mathrm{L}$. & Ev & Ex & $C A$ & LSK 130 \\
\hline Brunfelsia pauciflora (Cham. \& Schlecht.) Benth. & $\mathrm{Ab}$ & S-SE & $F A, A R$ & LDM 1120 \\
\hline Calibrachoa linoides (Sendtn.) Wijsman & Ev & S-SE (PS) & $F A, A R, C A$ & LDM 819 \\
\hline
\end{tabular}




\begin{tabular}{|c|c|c|c|c|}
\hline Família/Espécie & Hábito & Distr. Geogr. & Fisionomia & No. coletor \\
\hline Capsicum recurvatum (Witasek) Hunz. & $\mathrm{Ab}$ & S-SE-NE & $A R$ & LDM 1047 \\
\hline Cestrum bracteatum Link \& Otto & $\mathrm{Ab}$ & Neotrop. & $F A$ & LDM 416 \\
\hline Cestrum corymbosum Schltdl. & $\mathrm{Ab}$ & S-SE & $A R$ & LDM 821 \\
\hline Petunia mantiqueirensis T.Ando \& Hashim. & Ev & $\mathrm{SE}(\mathrm{CJ})$ & $\mathrm{CA}$ & LDM 1195 \\
\hline Solanum americanum Mill. & Ev & Neotrop. & $F A$ & $\begin{array}{c}\text { LSK } \\
33 / 2002\end{array}$ \\
\hline Solanum bradei Giacom. \& Stehmann & $\mathrm{Ab}$ & $\mathrm{SE}(\mathrm{CR})$ & $F A$ & LDM 1205 \\
\hline Solanum campaniforme Roem. ex Schult. & $\mathrm{Ab}$ & Neotrop. & $F A$ & LDM 1045 \\
\hline Solanum cassioides L.B.Sm. \& Downs & $\mathrm{Av}$ & S-SE (PS) & $F A, A R$ & LDM 579 \\
\hline Solanum diploconos (Mart.) Bohs & $\mathrm{Ab}$ & S-SE & $F A$ & LDM 724 \\
\hline Solanum enantiophyllanthum Bitter & $\mathrm{Ab}$ & SE (ML) & $F A, A F$ & LDM 455 \\
\hline Solanum granulosoleprosum Dunal & $\mathrm{Av}$ & S-SE-NE-CO (CS) & $F A, A R$ & LDM 440 \\
\hline Solanum guaraniticum A.St.-Hil. & $\mathrm{Ab}$ & S-SE (CS) & $F A, C A$ & LDM 740 \\
\hline Solanum inodorum Vell. & Ln & S-SE (PS) & $A R$ & LDM 818 \\
\hline Solanum megalochiton Mart. & $\mathrm{Ab}$ & S-SE-NE-CO & $A R$ & LDM 405 \\
\hline Solanum melissarum Bohs & $\mathrm{Ab}$ & S-SE-NE & $F A$ & LDM 493 \\
\hline Solanum pseudoquina A.St.-Hil. & $\mathrm{Av}$ & S-SE-NE (CS) & $F A$ & LDM 668 \\
\hline Solanum sellowianum Sendt. & $\mathrm{Ab}$ & S-SE-NE & $A R$ & LDM 472 \\
\hline Solanum vaillantii Dunal & $\mathrm{Ab}$ & S-SE-CO & $F A$ & LDM 728 \\
\hline Solanum velleum Thunb. & $\mathrm{Av}$ & S-SE-CO & $F A$ & LDM 376 \\
\hline \multicolumn{5}{|l|}{ Styracaceae } \\
\hline Styrax leprosus Hook. \& Arn. & $\mathrm{Av}$ & S-SE (CS) & $A R$ & LDM 811 \\
\hline \multicolumn{5}{|l|}{ Symplocaceae } \\
\hline Symplocos celastrinea Mart. & $\mathrm{Av}$ & S-SE-NE-CO (CS) & $F A$ & LDM 958 \\
\hline Symplocos falcata Brand & $\mathrm{Av}$ & $\mathrm{SE}(\mathrm{ML})$ & $F A$ & LDM 604 \\
\hline Symplocos pentandra (Mattos) Occhioni ex Aranha & $\mathrm{Ab}$ & S-SE (PS) & $C A$ & LDM 1256 \\
\hline Symplocos uniflora (Pohl) Benth. & $\mathrm{Av}$ & S-SE (CS) & $A R$ & LDM 823 \\
\hline \multicolumn{5}{|l|}{ Theaceae } \\
\hline Laplacea fructicosa (Schrad.) Kobuski & $\mathrm{Av}$ & AndNorte & $F A, A R$ & LDM 524 \\
\hline \multicolumn{5}{|l|}{ Thymelaeaceae } \\
\hline Daphnopsis fasciculata (Meisn.) Nevling & $\mathrm{Ab}$ & S-SE-CO & $F A, A R$ & LDM 304 \\
\hline \multicolumn{5}{|l|}{ Turneraceae } \\
\hline Turnera oblongifolia Cambess. & $\mathrm{Ab}$ & S-SE-NE-CO & $C A$ & LDM 1081 \\
\hline \multicolumn{5}{|l|}{ Verbenaceae } \\
\hline Glandularia lobata (Vell.) P.Peralta \& Thode & $\mathrm{Ev}$ & S-SE & $F A$ & LDM 642 \\
\hline Glandularia phlogiflora (Cham.) Schnack \& Covas & Ev & S-SE-CO & $C A$ & LDM 525 \\
\hline Lantana fucata Lindl. & $\mathrm{Ab}$ & Neotrop. & $F A, A F$ & LDM 336 \\
\hline Verbena litoralis Kunth & $\mathrm{Ab}$ & America & $A F$ & LDM 985 \\
\hline \multicolumn{5}{|l|}{ Violaceae } \\
\hline Anchietea pyrifolia (Mart.) G.Don & Ln & S-SE-NE-CO & $F A$ & LDM 1179 \\
\hline Hybanthus parviflorus (Mutis ex. L.f.) Baill. & Ev & Andes & $C A$ & LDM 1243 \\
\hline Viola subdimidiata A.St.-Hil. & Ev & SE (ML) & $F A$ & LDM 782 \\
\hline \multicolumn{5}{|l|}{ Vivianiaceae } \\
\hline Caeserea albiflora Cambess. & Ev & S-SE-CO & $C A$ & LDM 1258 \\
\hline \multicolumn{5}{|l|}{ Winteraceae } \\
\hline Drimys brasiliensis Miers & $\mathrm{Av}$ & S-SE-NE-CO & $F A, A R, A F$ & LDM 467 \\
\hline \multicolumn{5}{|l|}{ Xyridaceae } \\
\hline Xyris rigida Kunth & Ev & S-SE (PS) & $A F$ & LDM 777 \\
\hline Xyris wawrae Heimerd & Ev & SE (ML) & $A F$ & LDM 686 \\
\hline
\end{tabular}




\section{Discussão}

A Floresta Atlântica e o norte dos Andes são regiões tropicais montanhosas sul-americanas que concentram uma elevada riqueza de espécies endêmicas e são consideradas um dos hotspots mundiais de diversidade de angiospermas (Myers et al. 2000; Kier et al. 2009). A riqueza observada em Monte Verde foi similar à verificada em outros maciços de altitude do Sul e Sudeste brasileiros. Enquanto a riqueza específica nos maciços de altitude litorâneos com levantamentos florísticos disponíveis na região Sudeste variou de 347 a 531 espécies, na região Sul variou entre 236 e 354 espécies (Brade 1951; Rambo 1956; Falkenberg 2003; Mocochinski \& Scheer 2008). Entretanto, o escasso número de levantamentos florísticos ainda não permite comparações mais precisas para confirmarmos se há diferenças significativas na riqueza de espécies entre as áreas de altitude atlânticas ao longo do gradiente latitudinal da porção sul da Floresta Atlântica (Martinelli 2007).

Asteraceae, Cyperaceae, Fabaceae, Melastomataceae, Myrtaceae, Orchidaceae, Rubiaceae e Solanaceae foram as famílias mais ricas em Monte Verde, apresentando 236 espécies, $47,3 \%$ do total de espécies coletadas. A elevada riqueza dessas famílias ora esteve associada à diversidade de hábitos, por suas espécies ocuparem diferentes estratos da vegetação, ou por estarem presentes em todas as formações vegetacionais coletadas. Elas também apresentaram elevada riqueza em levantamentos realizados em Campos de Jordão e no Planalto do Itatiaia e estão entre as famílias mais ricas na Serra da Mantiqueira Meridional (Brade 1956; Robim et al. 1990; Mattos \& Mattos 1982; Meireles 2009). Ericaceae, Euphorbiaceae, Lamiaceae, Lauraceae, Malvaceae e Piperaceae também foram famílias ricas e com espécies endêmicas da Serra da Mantiqueira ou restritas às áreas montanhosas das Regiões Sul e do Sudeste brasileiras.

A flora do Sudeste brasileiro comporta espécies ocorrentes em diferentes regiões fitogeográficas sul-americanas (Brade 1942; Smith 1962; Safford 2007). Gêneros neotropicais, austral-antárticos e pantropicais, indicadores de formações florestais de altitude, como Chusquea, Drimys, Ilex e Weinmannia estiveram presentes no estrato arbóreo da Floresta Altimontana em Monte Verde (Giulietti \& Pirani 1987; Gentry 1995; Hamilton et al. 1995). Abutilon, Escallonia, Macropeplus, Myrceugenia e Symplocos são outros gêneros arbóreos neotropicais, austral-antárticos ou pantropicais com espécies restritas e indicadoras de florestas altimontanas das Regiões Sul ou Sudeste brasileiros (Meireles et al. 2008; Scheer et al. 2011). Baccharis, Gaylussacia, Leandra, Mimosa, Salvia, Senecio e Tibouchina são gêneros arbustivos com uma elevada riqueza e um número representativo de espécies endêmicas em formações altimontanas (Meireles 2009; Mocochinski \& Scheer 2008). Anenome, Carex, Cunila, Eryngium, Galianthe, Griselinia, Luzula, Mikania, Peperomia, Polygala e Viola são gêneros com espécies herbáceas, epifíticas ou lianescentes também com espécies que ocorrem preferencialmente em formações altimontanas atlânticas (Safford 2007; Meireles 2009).

Uma composição florística diferenciada entre as formações vegetacionais foi observada. A Floresta Altimontana em Monte Verde apresentou um número representativo de famílias pouco comuns nas formações florestais em altitudes mais baixas do Sudeste brasileiro, como Aquifoliaceae, Cunoniaceae, Escalloniaceae, Proteaceae e Winteraceae (Oliveira-Filho \& Fontes 2000; França \& Stehmann 2004; Meireles et al. 2008; Bertoncello et al. 2011). Asteraceae, Lauraceae, Melastomataceae, Myrtaceae e Solanaceae, as

Tabela 2 - Número de total de espécies por tipo de vegetação e espécies compartilhadas entre as formações vegetacionais altimontanas do distrito de Monte Verde, Camanducaia, Minas Gerais.

Table 2 - Total number of species by vegetacional types and species shared between the upper montane vegetation types in the Monte Verde district, Camanducaia, State of Minas Gerais.

\begin{tabular}{lcccc}
\hline Formações & Floresta Altimontana & Floresta de Araucária & Afloramento Rochoso & Campo de Altitude \\
\hline Floresta Altimontana & 291 & 40 & 25 & 25 \\
Floresta de Araucária & 40 & 91 & 6 & 15 \\
Afloramento Rochoso & 25 & 6 & 87 & 11 \\
Campo de Altitude & 25 & 15 & 11 & 129 \\
\hline
\end{tabular}


Tabela 3 - Número de espécies por tipo de distribuição geográfica nas formações vegetacionais altimontanas do distrito de Monte Verde, Camanducaia, Minas Gerais. Distr. Geog.: Distribuição Geográfica; F.Alti.: Floresta Altimontana; F.Arac.: Floresta de Araucária; C.Alt.: Campo de Altitude; A.Rch.: Afloramento Rochoso; (Pp): porcentagem de espécies em relação ao total de espécies por formação vegetacional entre parênteses.

Table 3 - Number of species per geographic distribution patterns on the upper montane vegetation types in the Monte Verde district, Camanduacaia, State of Minas Gerais. Distr. Geog.: Geographic Patterns; F.Alti.: Upper montane Forest; F.Arac.: Araucaria Forest; C. Alt.: High-altitude grassland; A. Rch: Rocky outcrop. (Pp): percentage of species in relation of total species by vegetacional type between parentheses.

\begin{tabular}{lccccc}
\hline Distribuição Geográfica & $\begin{array}{c}\text { Floresta } \\
\text { Altimontana }\end{array}$ & $\begin{array}{c}\text { Floresta de } \\
\text { Araucária }\end{array}$ & $\begin{array}{c}\text { Campo de } \\
\text { Altitude }\end{array}$ & $\begin{array}{c}\text { Afloramento } \\
\text { Rochoso }\end{array}$ & F.Tot. \\
\hline SE & $43(14,7)$ & $5(5,5)$ & $9(7,0)$ & $13(14,9)$ & $61(12,2)$ \\
SE (CJ) & $4(1,3)$ & - & $1(0,8)$ & $1(1,1)$ & $5(1,0)$ \\
SE (MM) & $9(3,1)$ & - & - & - & $9(1,8)$ \\
SE (ML) & $20(6,9)$ & $3(3,3)$ & $6(4,6)$ & $10(11,5)$ & $32(6,4)$ \\
SE (CR) & $7(2,4)$ & - & $1(0,8)$ & $2(2,3)$ & $9(1,8)$ \\
SE-CO & $2(0,7)$ & - & $3(2,3)$ & - & $5(1,0)$ \\
SE-NE & $2(0,7)$ & $1(1,0)$ & $3(2,3)$ & $1(1,1)$ & $6(1,2)$ \\
SE-CO-NE-N & - & - & - & $1(1,1)$ & $1(0,2)$ \\
S-SE & $72(24,7)$ & $27(29,7)$ & $33(25,6)$ & $20(23,1)$ & $126(25,2)$ \\
S-SE (FA) & $10(3,4)$ & $2(2,2)$ & $3(2,3)$ & $5(5,7)$ & $17(3,4)$ \\
S-SE (PS) & $27(9,2)$ & $12(13,2)$ & $12(9,3)$ & $6(6,9)$ & $49(9,8)$ \\
S-SE-CO & $19(6,5)$ & $4(4,4)$ & $11(8,5)$ & $7(8,0)$ & $36(7,2)$ \\
S-SE-NE & $34(11,7)$ & $14(15,4)$ & $3(2,3)$ & $7(8,0)$ & $44(8,8)$ \\
S-SE-CO-NE & $23(7,9)$ & $9(9,9)$ & $16(12,4)$ & $2(2,3)$ & $41(8,2)$ \\
S-SE-CO-NE-N & $5(1,7)$ & $4(4,4)$ & $1(0,8)$ & $1(1,1)$ & $8(1,6)$ \\
S-SE-CO-N & $1(0,3)$ & - & $2(1,5)$ & - & $2(0,4)$ \\
Andes & $14(4,8)$ & $6(6,6)$ & $6(4,6)$ & $5(5,7)$ & $21(4,2)$ \\
Neotropical & $35(12)$ & $9(9,9)$ & $17(13,2)$ & $11(12,7)$ & $60(12)$ \\
AmSul & $11(3,8)$ & $3(3,3)$ & $8(6,2)$ & $2(2,3)$ & $20(4,1)$ \\
America & $9(3,1)$ & $3(3,3)$ & $6(4,6)$ & $4(4,7)$ & $19(3,9)$ \\
Exóticas & $7(2,5)$ & $2(2,2)$ & $4(3,2)$ & $1(1,1)$ & $14(2,9)$ \\
N.Classificadas & $14(4,9)$ & $4(4,4)$ & $7(5,5)$ & $12(13,9)$ & $35(7,1)$ \\
\hline
\end{tabular}

famílias mais ricas para o estrato arbóreo na Floresta Altimontana, são frequentes em outras formações florestais atlânticas, mas apresentam grande importância relativa na composição e na estrutura do estrato arbóreo em áreas de altitude atlânticas (Falkenberg \& Voltolini 1995; OliveiraFilho \& Fontes 2000; França \& Stehmann 2004; Meireles et al. 2008).

No estrato arbustivo da Floresta Altimontana, os gêneros Abutilon, Leandra, Salvia e Solanum destacaram-se pela elevada riqueza e por apresentarem espécies endêmicas da Serra da Mantiqueira. Rubiaceae, família rica no sub-bosque de florestas neotropicais, apresentou maior riqueza de espécies herbáceas do que arbustivas, o que também foi observado em Campos dos Jordão (Gentry \& Emmons 1987; Robim et al. 1990). No estrato herbáceo observou-se uma elevada riqueza de orquídeas terrestres e várias espécies de Cyperaceae. Bromeliaceae, apesar de não apresentar muitas espécies nesta floresta, esteve representada por espécies epífitas e terrícolas. Espécies epífitas do gênero Peperomia são frequentes, enquanto se destacam entre as lianas os gêneros Mikania e Oxypetalum, com espécies endêmicas à Mantiqueira Meridional.

Myrceugenia destacou-se como um gênero muito rico e dominante nas florestas altimontanas da porção sul da Floresta Atlântica (Klein 1960; Meireles et al. 2008; Scheer et al. 2011). Muitas das espécies brasileiras desse gênero ocorrem preferencialmente nas regiões planálticas da costa leste brasileira, em altitudes superiores a 900-1000 metros, e são espécies indicadoras das florestas altimontanas sob climas frios e úmidos (Landrum 1981; Meireles et al. 2008; Meireles 2009). A baixa riqueza de espécies arbóreas das 
famílias Bignoniaceae, Euphorbiaceae e Fabaceae, acompanhada pela total ausência de famílias ocorrentes em florestas estacionais e ombrófilas em altitudes mais baixas, como Chrysobalanaceae, Nyctaginaceae e Urticaceae, contribuem para uma forte diferenciação florística das florestas altimontanas na porção sul da Floresta Atlântica (Meireles et al. 2008; Scheer et al. 2011; Joly et al. 2012).

A Floresta de Araucária apresentou uma riqueza específica baixa e com cerca de $43 \%$ de suas espécies compartilhadas com a Floresta Altimontana. Araucaria angustifolia e Podocarpus lambertii predominam no estrato superior da floresta de Araucária em Monte Verde. É interessante resaltar que em uma estreita faixa na margem dos cursos d'água, Podocarpus lambertii domina o estrato superior florestal e Araucaria angustifolia está ausente. Eiten (1970) denominou essa formação de Floresta de Podocarpo, uma fisionomia aparentemente descrita somente em áreas de altitude da região Sudeste, também registrada para a Serra da Bocaina e Campos do Jordão (Brade 1951; Hueck 1972).

Asteraceae, Lauraceae e Myrtaceae representam as famílias com maior riqueza nas Florestas de Araucária (Los 2004). Entretanto, na Floresta de Araucária em Monte Verde, Solanaceae foi a família com maior número de espécies. Rambo (1956) também observou um compartilhamento de espécies arbóreas entre florestas altimontanas e florestas de Araucária nos Aparados da Serra e citou que a ausência de Araucaria angustifolia demarcaria os limites entre as florestas altimontanas e as matas de araucária. A Floresta de Araucária e a Floresta Altimontana em Monte Verde não diferem somente pela ausência de Araucaria angustifolia. Tanto o porte dos indivíduos arbóreos com um dossel que pode ultrapassar $20 \mathrm{~m}$ de altura e um baixo epifitismo briofítico constituído principalmente por liquens e epífitos fanerogâmicos na Floresta de Araucária promovem uma dissimilaridade fisionômica entre essas formações.

Algumas espécies, dentre árvores, arbustos, ervas e epífitas foram coletadas somente na Floresta de Araucária, como Aegiphila obducta, Azara uruguayensis, Styrax leprosus, Symplocos uniflora, Zanthoxylum rhoifolium, além dos arbustos, Leandra cordigera, Leandra hirtella $e$ Myrceugenia miersiana e epífitas como Hatiora salicornioides e Vriesea pardalina. Cestaro et al. (1986) registraram 28 espécies para o estrato herbáceo de um fragmento de floresta de Araucária, enquanto Polisel et al. (2014) encontraram de 48 a 93 espécies no estrato arbustivo e herbáceo em quatro áreas de floresta de Araucária no estado de São Paulo. Essas riquezas específicas são superiores à riqueza aqui registrada, necessitando um esforço amostral maior para caracterizar a composição e riqueza de espécies nos diferentes hábitos desta formação em Monte Verde.

Os Campos de Altitude em Monte Verde apresentaram uma expressiva riqueza específica composta por várias espécies com distribuição restrita à àreas de altitude das regiões Sul e Sudeste brasileiras. Essa formação vegetacional ocorre sobre solos relativamente desenvolvidos, apresentando similaridade fisionômica com os campos da região de Campos do Jordão e da Serra da Bocaina, onde áreas com rocha exposta são menos frequentes, diferentemente do que é observado no Planalto do Itatiaia. Áreas brejosas nesses campos constituem o habitat de várias espécies coletadas.

A riqueza observada nos Campos de Altitude foi menor do que a encontrada nos campos de altitude do Itatiaia e da Serra dos Órgãos provavelmente devido a sua menor extensão e alto impacto antrópico em Monte Verde (Safford 1999). Os Campos de Altitude de Monte Verde estão compostos por um sub-conjunto de espécies ocorrentes em áreas mais extensas de campos de altitude do Planalto de Campos de Jordão. Entretanto, Petunia mantiqueirensis representa uma espécie com ocorrência restrita à região de Camanducaia-Monte Verde (Kamino et al. 2102). Vale ressaltar também que outras sete espécies restritas a campos de altitude do Sudeste brasileiro apresentam populações nos Campos de Altitude em Monte Verde.

Asteraceae, Melastomataceae e Myrtaceae destacam-se pela elevada riqueza entre os táxons arbustivos nos campos de altitude atlânticos (Safford 1999; Mocochinski \& Scheer 2008). Para os demais hábitos tem se destacado as famílias Cyperaceae, Ericaceae, Eriocaulaceae, Iridaceae e Polygalaceae (Brade 1951; Mocochinski \& Scheer 2008). Poaceae, que apresenta destacada importância fisionômica em campos de altitude, apresentou poucas espécies, talvez pela adiantada degradação desses campos e dominância de algumas espécies. A maioria das espécies coletadas da família Fabaceae ocorreu nessa formação, 
sobretudo no estrato herbáceo-arbustivo. Baccharis, Gaylussacia, Mimosa e Tibouchina destacam-se nos campos de altitude por apresentarem várias espécies típicas de ambientes altimontanos ao sul da Floresta Atlântica (Brade 1956; Mocochinski \& Scheer 2008).

Safford (1999) sugeriu haver similaridades florísticas e fisionômicas entre os páramos andinos e os campos de altitude brasileiros. A semelhança fisionômica entre essas formações é evidenciada pela relativa similaridade climática, convergência de hábitos e por compartilharem gêneros ricos em formações montanas sul-americanas (Ribeiro et al. 2007). Dezessete espécies foram comuns entre essas formações, quando comparada com a listagem publicada por Luteyn (1999). Entretanto algumas apresentam comportamento ruderal ou são introduzidas, como Achyrocline satureioides, Arenaria lanuginosa, Chaptalia nutans, Fragaria vesca, Galium hypocarpium, Gamochaeta americana, Hypoxis decumbens, Poa anua e Trifolium repens. E outras são frequentes em áreas de altitude do Sudeste, como Cuscuta grandiflora, Hybanthus parviflorus, Myrsine coriacea, Myrsine umbellata, Peperomia galioides, Ranunculus fragelliformes e Sisyrinchium micranthum, que também ocorrem em outros tipos vegetacionais da região neotropical (Luteyn 1999).

Afloramentos rochosos geralmente comportam um número menor de espécies em áreas florestais, mas apresentam uma flora distinta da vegetação do entorno (Sarthou \& Villiers 1998; Barthlott et al. 1993). Em Monte Verde, os Afloramentos Rochosos estão envoltos por matriz florestal e observa-se a formação de um escrube pouco extenso nas suas bordas. Asteraceae, Cyperaceae, Melastomataceae, Orchidaceae, Poaceae, Polygalaceae e Rubiaceae estão entre as famílias mais ricas nos afloramentos rochosos imersos em formações florestais no Sudeste brasileiro (Meirelles et al. 1999; Safford \& Martinelli 2000; Caiafa \& Silva 2007; Ribeiro et al. 2007). Cyperaceae geralmente não é citada como uma das famílias mais ricas em afloramentos rochosos no Sudeste, entretanto espécies dessa família são citadas como as principais espécies formadoras das ilhas de vegetação sobre afloramentos graníticos e sobre nifelina-sienito no Sudeste do Brasil (Caiafa \& Silva 2007; Medina et al. 2006).

Octomeria sp. e Hatiora herminiae foram as únicas espécies observadas que se instalaram diretamente sobre a rocha. Aechmea disticantha destacou-se entre as fanerófitas como a principal formadora das ilhas de vegetação nos afloramentos de Monte Verde. Essa espécie é também observada em afloramentos ao sul da Mantiqueira Meridional, como em Atibiaia e Extrema (Meirelles 1996; Yamamoto 2009). Outras monocotiledôneas rizomatosas ou bulbosas, como Alstroemeria isabelleana e Hyppeastrum morelianum, são visualmente frequentes nas ilhas de vegetação. Algumas fanerógamas com órgãos subterrâneos espessados também foram observadas, como Sinningia magnifica, Stevia decussata e Tibouchina mosenii. Algumas espécies arbustivas ocorrem preferencialmente nas bordas dos afloramentos rochosos como Abatia glabra, Dasyphyllum flagellare, Verbesina glabrata e Crotalaria miottoae.

Um conjunto das espécies coletadas no distrito de Monte Verde esteve restrito às formações florestais e campestres altimontanas da Serra da Mantiqueira ou foi compartilhado com outros maciços litorâneos com clima subtropical de altitude no Sudeste brasileiro. A Floresta Altimontana e os Afloramentos Rochosos foram as formações que apresentaram as maiores proporções de espécies restritas à região Sudeste brasileira. Leitão-Filho (1982) destacou a ocorrência de espécies com distribuição geográfica restrita às áreas montanhosas sob um clima mais frio e com forte influência de neblina e com geadas frequentes no período mais seco do ano na Serra da Mantiqueira. Croton organensis, Euplassa itatiaiae, Macropeplus dentatus e Symplocos falcata são exemplos de espécies arbóreas que ocorrem somente em florestas altimontanas do Sudeste brasileiro.

Hatiora herminiae, Myrceugenia brevipedicellata, Ocotea virgultosa, Petunia mantiqueirensis e Manettia congesta também são espécies endêmicas da Serra da Mantiqueira Meridional e estão restritas ao Planalto de Campos do Jordão. Abatia glabra, Abutilon itatiaiae, Euplassa itatiaie, Hyptis propinqua, Peperomia subternifolia, Mikania camporum, Mimosa monticola, Salvia campos-portoi e Salvia sellowiana também ocorrem no Planalto do Itatiaia. Eryngium proliferum, descrito para a Serra do Itatiaia e coletado no município de São Paulo, representa um registro novo para o estado de Minas Gerais (Corrêa \& Pirani 2005). Leandra gynoverrucosa, Crotalaria miottoae e Solanum bradei são exemplos de espécies recém- 
descritas presentes em Monte Verde que ocorrem em ambientes montanos do Sudeste brasileiro (Flores \& Tozzi 2005; Reginato 2011; Giacomin \& Stehmann 2014).

A maioria das espécies registradas para Monte Verde também ocorrem nos campos de altitude e nas florestas de Araucária sobre os planaltos da Região Sul do país. Essas duas formações destacaram-se com as maiores proporções de espécies ocorrentes somente nas regiões Sul e Sudeste brasileiras. Um conjunto menor de espécies está restrito às florestas altimontanas das regiões Sul e do Sudeste brasileiras, como Baccharis oreophilla, Ilex taubertiana e Myrceugenia ovalifolia (Barroso 1976; Landrum 1984; Groppo Jr. \& Pirani 2002). Para algumas dessas espécies, as terras altas da Serra da Mantiqueira representam o limite de ocorrência setentrional e várias delas apresentam uma distribuição geográfica disjunta entre as terras altas do Sudeste e a Região Sul do Brasil. Algumas delas são registros novos de ocorrência para o estado de Minas Gerais, como Desmodium triarticulatum, Mimosa filipetiola, Myrceugenia ovalifolia e Solanum cassioides, antes conhecidas somente para a Região Sul do Brasil (Burkart 1979; Azevedo 1981; Landrum 1984; Mentz \& Oliveira 2004).

A manutenção de populações dessas espécies nos maciços de altitude da região Sudeste está associada à ocorrência de um clima subtropical de altitude, caracterizado por temperaturas mínimas mais acentuadas e a ocorrência de geadas, como observado nos planaltos sulinos (Azevedo 1962; Brade 1956; Segadas-Viana \& Dau 1965). Azevedo (1962) sugeriu que a vegetação atual da Serra da Mantiqueira foi condicionada por condições paleo-climáticas diferentes das atuais. Mudanças climáticas quaternárias têm sido evocadas para explicar a ocorrência da floresta de Araucária nas áreas de altitude da região Sudeste brasileira e podem estar envolvidas na explicação de padrões de distribuição disjuntos das espécies ocorrentes nas áreas de altitude do Sul e Sudeste (Ledru et al. 1998; Behling 1998).

Registros palinológicos sugerem que formações campestres podem ter dominado a paisagem nos planaltos da Região Sul e que as formações florestais estariam menos extensas, em uma época mais fria e seca no Último Máximo Glacial (Behling 1998). Neste mesmo momento, na região Sudeste, as áreas de altitude apresentavam formações campestres mais extensas e as condições climáticas adequadas para o desenvolvimento de espécies florestais de ambientes mais frios estariam presentes em altitudes menores do que observado atualmente (Behling 1998; Meireles 2009).

O reestabelecimento das condições tropicais na América do Sul durante o Holoceno teria promovido tanto o deslocamento dessas espécies em direção às áreas mais elevadas na região Sudeste brasileira, como também o aumento de pequenas manchas florestais remanescentes nessas áreas durante o Último Máximo Glacial (Ledru et al. 2005). Com o aumento da temperatura e reestabelecimento dos níveis de precipitação atuais no Holoceno, regiões como o Planalto Atlântico Paulista foram reocupadas por outras espécies tolerantes a climas mais quentes (Ledru et al. 2005; Meireles 2009). A distribuição geográfica disjunta entre populações de espécies atualmente ocorrentes nos planaltos da Região Sul e nas regiões de altitude do Sudeste brasileiro, e até o momento não conhecidas para o Planalto Atlântico Paulista, pode ter sido estabelecida neste período (Meireles 2009).

Outro conjunto de espécies ocorreu somente nos campos rupestres e campos cerrados de Minas Gerais, Goiás e Bahia, ou também em formações campestres sulinas. O Campo de Altitude apresentou a maior proporção de espécies ocorrentes nas regiões Centro-Oeste e Nordeste. Algumas dessas espécies pertencem a gêneros ricos nos campos rupestres, com algumas espécies que ocorrem em áreas de altitude litorâneas. A ocorrência de espécies de campos rupestres nos campos de altitude da Serra da Mantiqueira mostra que essa formação também compartilha espécies de diferentes regiões fitogeográficas sul-americanas (Brade 1956; Peron 1989; Safford 1999; Safford 2007).

Achryrocline satureioides, Aspilia foliacea, Baccharis crispa, Cambessedessia espora var. ilicifolia, Declieuxia fruticosa, Eriope crassipes, Irlbachia pendula, Siningia allagophylla e Tibouchina frigidula são exemplos de espécies compartilhadas com campos cerrados (Durigan et al. 2004). Entretanto, as pequenas manchas de cerrado anteriormente observadas na Serra da Mantiqueira Meridional em Monte Verde (Azevedo 1962) foram localmente extintas provavelmente devido à mudanças no uso do solo. Várias dessas espécies foram observadas somente em um local, que atualmente encontra-se totalmente descaracterizado. 
Para as espécies restritas ao Sudeste, ao Nordeste ou Centro-Oeste, os maciços montanhosos litorâneos da região Sudeste podem estar atuando como uma barreira geográfica e representarem seu limite austral de ocorrência. As espécies campestres com este tipo de distribuição geográfica possivelmente toleram tanto uma maior estacionalidade climática, quanto temperaturas mínimas mais acentuadas e a ocorrência de geadas nas áreas de altitude austrais na região Sudeste (Alves et al. 2007; Vasconcelos 2011). Algumas espécies florestais frequentes em formações altimontanas da Região Sul e da Serra Mantiqueira, como Drimys brasiliensis, Pimenta pseudocaryophyllus, Rhamnus shpaerosperma e Roupala rhombifolia, também possuem populações em fragmentos florestais na Cadeia do Espinhaço e na Chapada Diamantina, alcançando as vezes o Maciço Goiano (Kamino et al. 2008; Nascimento et al. 2010). Nesses maciços montanhosos, efeitos compensatórios locais que promovam maior umidade no solo e a formação de baixos estratos de nuvens, garoa e neblina, podem estar associados à ocorrência dessas espécies (Santos et al. 2011; Kamino et al 2008; Nascimento et al. 2010).

Muitas das espécies com distribuição neotropical ou restritas à América do Sul apresentaram um padrão de distribuição periamazônico e para várias delas a ocorrência na América do Sul acompanha as principais cadeias montanhosas (Granville 1992; Safford 2007). Dentre as espécies observadas em regiões montanas andinas, foi observado um maior número de espécies que nas regiões andinas tropicais, algumas delas com populações conhecidas ao longo do Brasil Central, do que com as em regiões austrais da Cordilheira dos Andes (Safford 2007; Oliveira-Filho \& Ratter 2000). Uncinia hamata, por exemplo, ocorre em formações montanas da América Central, ao longo dos Andes, e no Brasil foi coletada até o momento na Serra do Caparaó e em Monte Verde. Griscelina ruscifolia é um exemplo de espécie marítimo-temperada chilena, também observada em formações altimontanas atlânticas (Barros 2002). Entretanto estudos filogeográficos são necessários para testar o monofiletismo e para confirmar as possíveis rotas migratórias dessas espécies que ocorrem entre as cadeias montanhosas sul-americanas (Safford 2007; Murillo-A et al. 2012).

A presença de espécies endêmicas e de espécies com distribuição geográfica restrita em diferentes famílias destaca a importância biogeográfica e evolutiva das áreas montanhosas litorâneas para a manutenção e promoção da alta riqueza florística na Floresta Atlântica. A conservação da Serra da Mantiqueira torna-se ainda extremamente necessária, pois ela pode representar o limite meridional de espécies restritas ao Sul e Sudeste; o limite austral de espécies ocorrentes no Sudeste, Centro-Oeste e Nordeste; além de manter populações de espécies com ocorrência na região andina e de outras regiões montanas sul-americanas e uma considerável riqueza de espécies restritas a ambientes altimontanos do Sudeste brasileiro.

Entretanto, as distintas formações vegetacionais em Monte Verde apresentam diferentes níveis de conservação e tipos de pressão antrópica. A cadeia local da Serra da Mantiqueira é uma das principais atrações turística no distrito e é a principal área de ocorrência da Floresta Altimontana e dos Afloramentos Rochosos. A Floresta Altimontana é impactada pelo bosqueamento em loteamentos, abertura de trilhas e presença de equinos, enquanto o pisoteio humano e retirada de plantas bulbosas impactam os Afloramentos Rochosos. Os Campos de Altitude são a formação mais impactada pela ocupação humana e poucas áreas permaneceram. Veloso (1992) destacou que as florestas de Araucária do Planalto de Campos do Jordão estariam em melhor estado de conservação que aqueles do Planalto do Itatiaia, mas poucas áreas em Monte Verde apresentam-se em bom estado de conservação, bem como para a Floresta de Podocarpus. Estratégias conservacionistas distintas podem ser pensadas para essas formações, como já listado no Plano de Manejo da APA Fernão Dias (IEF 2008).

A Serra da Mantiqueira representa a região com a maior área de ocupação da Floresta de Araucária e das demais formações altimontanas na região Sudeste brasileira (Hueck 1972; Safford 1999). O esforço de coleta diferencial entre as formações sugere que novas coletas, principalmente nas Florestas de Araucária, devem continuar a enriquecer a lista de espécies ocorrentes no distrito de Monte Verde. A provável extinção local de espécies coletadas na década de 1970, como Escallonia farinacea, Mimosa myriophylla, Salvia confertiflora e outras, associada às demais pressões antrópicas citadas, destaca a importância ao incentivo de diversas atividades conservacionistas. 
Atividades integradas entre a sociedade e órgãos institucionais competentes, a recuperação de áreas nativas, a criação de unidades de conservação privadas e governamentais para a manutenção da paisagem, bem como ações para a conservação de espécies endêmicas e de distribuição geográfica restrita e a fiscalização do extrativismo na região devem ser estimuladas. Levantamentos florísticos em regiões ainda pouco exploradas da Serra da Mantiqueira e de outros maciços de altitude do Sudeste brasileiro poderão futuramente ampliar o conhecimento da distribuição das espécies típicas de ambientes altimontanos da Floresta Atlântica.

\section{Agradecimentos}

Os autores agradecem à Capes, a bolsa de mestrado concedida ao primeiro autor e à Fapesp, o auxílio à pesquisa (Processo 01/07245), a Pós-Graduação em Biologia Vegetal do Instituto de Biologia da Unicamp e ao Herbário UEC. Aos taxomistas da UFMG, UFJF, UFSJ, UFU, Universidade Santa Úrsula, JBRJ, IBt, IF, USP, UFV, UFPR, UFRGS e UEFS, o auxílio na identificação das espécies. A Gustavo Carvalho, o auxílio na utilização do Pacote 'flora' e a Gustavo Shimizu, o tratamento das fotos. Ao Instituto Estadual de Florestas de Minas Gerais, à Companhia Melhoramentos Florestal e aos proprietários das áreas coletadas, as autorizações e apoio concedidos e aos assessores, o incentivo e valiosas contribuições.

\section{Referências}

Almeida, F.F.M. \& Carneiro, C.D. 1998. Origem e evolução da Serra do Mar. Revista Brasileira de Geociências 28: 135-150.

Alves, R.J.V.; Cardin, L. \& Kropf, M.S. 2007. Angiosperm disjunction "Campos rupestres - restingas": a reevalution. Acta Botanica Brasilica 21: 675-685.

APG III. 2009. An update of the Angiosperm Phylogeny Group classification for orders and families of flowering plants: APG III. Botanical Journal of Linnean Society 161: 105-121.

Azevedo, L.G. 1962. Tipos de vegetação do sul de Minas e campos da Mantiqueira (Brasil). Anais da Academia Brasileira de Ciências 34: 225-234.

Azevedo, A.M.G. 1981. O gênero Desmodium Desv. no Brasil: considerações taxonômicas. Tese de Mestrado. Universidade Estadual de Campinas, Campinas. 315 p.

Barbi, F. 2007. Capital social e ação coletiva na gestão das bacias dos rios Piracicaba, Capivari e Jundiaí: os desafios da gestão compartilhada do Sistema
Cantareira - SP. Tese de Mestrado. Universidade de São Paulo, São Paulo. 158 p.

Barros, F. 2002. Cornaceae. In: Wanderley, M.G.L., Shepherd, G.J. \& Giulietti, A.M. (eds.). Flora fanerogâmica do estado de São Paulo. Vol 2. Fapesp, Editora Hucitec, São Paulo. Pp. 93-94.

Barroso, G.M. 1976. Composite-Subtribo Baccharidinae Hoffmann - Estudo das espécies ocorrentes no Brasil. Rodriguésia 40: 3-273.

Barthlott, W.; Gröger, A. \& Porembski, S. 1993. Some remarks on the vegetation of tropical inselberg: diversity and ecological differentiation. Biogeographica 69: 105-124.

Behling, H. 1998. Late Quaternary vegetational and climatic changes in Brazil. Review of Paleobotany and Palynology 99: 143-156.

Berg, E.V.D. \& Oliveira-Filho, A.T. 2000. Composição florística e estrutura fitossociológica de uma floresta ripária em Itutinga, MG, e comparação com outras áreas. Revista Brasileira de Botânica 23: 231-253.

Bertoncello, R.; Yamamoto, K.; Meireles, L.D.; Shepherd, G.J. 2011. A phytogeographic analysis of cloud forests and other forest subtypes amidst the Atlantic forests in south and southeast Brazil. Biodiversity and Conservation 20: 3413-3433.

Brade, A.C. 1942. A composição da flora pteridófita do Itatiaia. Contribuição à fitogeografia dessa região. Rodriguésia 6: 23-43.

Brade, A.C. 1951. Relatório da excursão à Serra da Bocaina, no estado de São Paulo. Rodriguésia 15: 55-66.

Brade, A.C. 1956. A flora do Parque Nacional do Itatiaia. Boletim do Parque Nacional do Itatiaia 5: 1-114.

Burkart, A. 1979. Leguminosas - Mimosoideas. In: Reitz, P. (ed.). Flora ilustrada catarinense. Herbário Barbosa Rodrigues. 359 p.

Carvalho, G. H. 2014. Package 'flora'. Disponível em $<$ http://cran.r-project.org/web/packages/flora/flora. pdf $>$. Acesso em 10 junho 2014.

Caiafa, A.N. \& Silva, A.F. 2007. Structural analysis of the vegetation on a highland granitic rock outcrop in Southeast Brazil. Revista Brasileira de Botânica 30: 657-664.

Cestaro, L.A.; Waechter, J.L. \& Baptista, L.R. 1986. Fitossociologia do estrato herbáceo da mata de araucária da Estação Ecológica de Aracuri, Esmeralda, RS. Hoehnea 13: 59-72.

Corrêa, I.P. \& Pirani. 2005. Apiaceae. In: Wanderley, M.G.L.; Shepherd, G.J.; Giulietti, A.M. \& Melhem, T.S. (eds.). Flora fanerogâmica do estado de São Paulo. Vol 4. Fapesp: Rima, São Paulo. Pp. 11-34.

Costa, C.M.R.; Hermann, G.; Martins, C.S.; Lins, L.V. \& Lamas, I.R. (orgs.). 1998. Biodiversidade em Minas Gerais: um atlas para sua conservação. Fundação Biodiversitas, Belo Horizonte. 94p. 
Costa, C. \& Herrmann, G. 2006. O corredor ecológico da Mantiqueira In: Costa, C.M.R.; Hermann, G.; Pinto, I.A. \& Costa, P.A.M. (eds.). Plano de ação do corredor ecológico da Mantiqueira. Valor Natural, Belo Horizonte. Pp. 13-29.

CRIA - Centro de Referência em Informação Ambiental. 2001. speciesLink. Disponível em $<$ http://splink. cria.org.br/tools? criaLANG $=\mathrm{pt}>$. Acesso em 10 junho 2014.

Durigan, G.; Baitello, J.B.; Franco, G.A.D.C. \& Siqueira, M.F. 2004. Plantas do cerrado paulista: imagens de uma paisagem ameaçada. Páginas \& Letras, São Paulo. 475p.

Dusén, P.K.H. 1955. Contribuições para a flora do Itatiaia. Parque Nacional do Itatiaia. Boletim 4: 67-91.

Eiten, G. 1970. A vegetação do Estado de São Paulo. Boletim do Instituto de Botânica 7:1-77.

Falkenberg, D.B. 2003. Matinhas nebulares e vegetação rupícola dos Aparados da Serra Geral (SC/RS), sul do Brasil. Tese de Doutorado. Universidade Estadual de Campinas, Campinas. 558p.

Falkenberg, D.B. \& Voltolini, J.C. 1995. The montane cloud Forest in southern Brazil. In: Hamilton, L.S.; Juvik, J.O. \& Scatena, F.N. (orgs.). Tropical Montane Cloud Forest. Spring-Verlag Inc, Nova York. Pp. 138-149.

Flores, A.S. \& Tozzi, A.M.G.A. 2005. A new species of Crotalaria L. (Leguminosae-Papilionoideae) from Southeastern Brazil. Novon 15: 418-420.

Font Quer, P. 1975. Diccionario de botánica. Editora Labor, Barcelona. 1244 p.

Forzza, R.C. et al. 2012. Lista de espécies da flora do Brasil. Disponível em <http://reflora.jbrj. gov.br/jabot/listaBrasil/ConsultaPublicaUC/ ConsultaPublicaUC.do.>. Acesso em 10 junho 2014.

França, G.S. \& Sethmann, J.R. 2004. Composição florística e estrutura do componente arbóreo de uma floresta altimontana no município de Camanducaia, Minas Gerais, Brasil. Revista Brasileira de Botânica 27: 19-30.

Galindo-Leal, C. \& Câmara, I.G. 2005. Status do hotspot Mata Atlântica: uma síntese. In: Galindo-Leal, C. \& Câmara, I.G, (eds.). Mata Atlântica: biodiversidade, ameaças e perspectivas. Fundação SOS Mata Atlântica, São Paulo, Conservação Internacional, Belo Horizonte. Pp. 3-11.

Gentry, A.H. 1995. Patterns of diversity and floristic composition in neotropical montane forest. In: Churchill, S.P.; Baslev, H.; Forero, E. \& Luteyn, J.L. (eds.). Biodiversity and conservation of neotropical montane forest. The New York Botanical Garden Press, Nova York. Pp. 103-126.

Gentry, A.H. \& Emmons, L.H. 1987. Geographical variation in fertility, phenology, and composition of the understory of neotropical forests. Biotropica 19: 216-227.
Giacomin, L. \& Stehmann, J. R. 2014. Three new species of Solanum (Brevantherum Clade) endemic to the Brazilian Atlantic Forest. Phytokeys 38: 69-87.

Giulietti, A.M. \& Pirani, J.R. 1987. Patterns of geographic distribution of some plant species from the Espinhaço Range, Minas Gerais and Bahia, Brazil. In: Vanzolini, P.E. \& Heyer, W.R. (eds.). Proceedings of a workshop on neotropical distribution patterns. Academia Brasileira de Ciências, Rio de Janeiro. Pp. 39-69.

Golfari, L. 1975. Zoneamento ecológico do estado de Minas Gerais para reflorestamento. Série Técnica, Número 3. 65p.

Granville, J. 1992. Un cas de distribution particulier: les species forestieres peri-amazoniennes. Rendu dus Séances de la Societé de Biogéographie 68: 1-33.

Groppo Jr., M. \& Pirani. 2002. Aquifoliaceae. In: Wanderley, M.G.L.; Shepherd, G.J. \& Giulietti, A.M. (eds.). Flora fanerogâmica do estado de São Paulo. Vol 2. Fapesp: Editora Hucitec, São Paulo. Pp. 31-37.

Hamilton, L.S.; Juvik, J.O. \& Scatena, F.N. 1995. The Puerto Rico tropical cloud forest symposium: introduction and workshop synthesis. In: L.S. Hamilton, LS.; Juvik, J.O. \& Scatena, F.N. (eds.). Tropical montane cloud forest. Springer-Verlag, New York. Pp. 1-23.

Himura, S.T.; Riccomini, C. \& Modenesi-Gauttieri, M.C. 2001. Neotectônica no planalto de Campos do Jordão, SP. Revista Brasileira de Geociências 31: 375-384.

Hueck, K. 1972. As florestas da América do Sul. Editora da Universidade de Brasília, Brasília. 466p.

IBGE. 2012. Manuel técnico da vegetação brasileira. Instituto Brasileiro de Geografia e Estatística, Rio de Janeiro. 271p.

IEF. 2008. Plano de manejo - APA Fernão Dias. Disponível em <http://:www.ief.mg.gov.br/images/ stories/Plano_de_Manejo/fernao_dias/item08 programas.pdf. $>$. Ácesso em 6 de junho de 2014.

Joly, C.A.; Assis, M.A.; Bernacii, L.C.; Tamashiro, J.Y.; Campos, M.C.R.; Gomes, J.A.M.A.; Lacerda, M.S.; Santos, F.A.M.; Pedroni, F.; Pereira, L.S.; Padgurschi, M.C.G.; Prata, E.M.B.; Ramos, E.; Torres, R.B.; Rochelle, A.; Martins, F. R.; Alves, L.F.; Vieira, S.A.; Martinelli, L.A.; Camargo, P.B.; Aidar, M.P.M.; Eisenlohr, P.V.; Simões, E.; Villani, J.P. \& Belinello, R. 2012. Florística e fitossociologia em parcelas permanentes da Mata Atlântica do Sudeste do Brasil ao longo de um gradiente altitudinal. Biota Neotropica 12: 123-145.

Kamino, L.H.Y.; Oliveira-Filho, A.O. \& Stehmann, J.R. 2008. Relações florísticas entre as fitofisionomias florestais da Cadeia do Espinhaço, Brasil. Megadiversidade 4: 38-72.

Kamino, L.H.Y.; Siqueira, M.F.; Sánchez-Tapia, A. \& Stehmann, J.R. 2012. Reassessment of the extinction risk of endemic species in the 
Neotropics: How can modelling tools help us? Natureza \& Conservação 10: 191-198.

Kier, G.; Kreft, H.; Lee, T.M.; Jetz, W.; Ibisch, P.L.; Nowicki, C.; Mutke, J. \& Barthlott, W. 2009. A global assessment of endemism and species richness across island and mainland regions. Proceeding of the National Academy of Sciences of the United State of America 106: 9322-9327.

Klein, R.M. 1960. O aspecto dinâmico do pinheiro brasileiro. Sellowia 12: 17-45.

Landrum, L.R. 1981. A monograph of the genus Myrceugenia (Myrtaceae). Flora Neotropica. Vol. 29. The New York Botanical Garden, New York. 137 p.

Landrum, L.R. 1984. Taxonomic implications of the discovery of calyptrate species of Myrceugenia (Myrtaceae). Brittonia 36: 161-166.

Ledru, M-P.; Salgado-Labouriau, M.L. \& Lorscheitter, M.L. 1998. Vegetation dynamics in southern and central Brazil during the last 10,000 yr B.P. Review of Palaeobotany and Palynology 99: 131-142.

Ledru, M.-P.; Rousseaub, D.D.; Cruz Jr. F.W.; Riccomini, C.; Karmanna, I. \& Martin, L. 2005. Paleoclimate changes during the last $100,000 \mathrm{yr}$ from a record in the Brazilian Atlantic rainforest region and interhemispheric comparison. Quaternary Research 64: 444-450.

Leitão-Filho, H.F. 1982. Aspectos taxonômicos das florestas do estado de São Paulo. Silvicultura em São Paulo 16: 197-296.

Los, M.M. 2004. Florística, estrutura e diversidade da floresta com Araucária em áreas de diferentes tamanhos. Tese de Mestrado. Universidade de São Paulo, São Paulo. 125p.

Luteyn, J.L. 1999. Páramos: a checklist of plant diveristy, geografhical distribution, and botanical literature. Memoirs of the New York Botanical Garden, Nova York. Vol. 84. 278p.

Machado-Filho, L.; Ribeiro, M. W.; Gonzales, S. R.; Schenini, C. A.; Santos-Neto, A.; Palmeira, R.C.B.; Pires, J.L.; Teixeira, W. \& Castro, H.E.F. 1983. In: Projeto RADAMBRASIL. Geologia. Folhas SF:23/24 Rio de Janeiro/Vitória. Vol. 32. Rio de Janeiro-RJ. Pp. 56-66.

Martinelli, G. 2007. Mountain biodiversity in Brazil. Revista Brasileira de Botânica 30: 587-597.

Martins, C.S. 2000. Caracterização física e fitogeográfica de Minas Gerais. In: Mendonça, M.P. \& Lins, LV. (orgs.). Lista vermelha das espécies ameaçadas de extinção da flora de Minas Gerais. Fundação Biodiversitas, Belo Horizonte. Pp. 35-43.

Mattos, J.R. \& Mattos, N.F. 1982. Contribuição ao conhecimento da Flora do Parque Estadual de Campos do Jordão. Silvicultura em São Paulo 14: 647-662.
MBG - Missouri Botanical Garden. 2014. Tropicos.org. Disponível em $<$ http://www.biologie.uni-hamburg. de/b-online/ibc99/mobot/pick.html > Acesso em 10 junho 2014.

Medina, B.O.; Ribeiro, K.T. \& Scarano, F.R. 2006. Plant-plant and plant-topography interactions on a rock outcrop at high altitude in Southeastern Brazil. Biotropica 38: 27-34.

Meireles, L.D.; Shepherd, G.J. \& Kinoshita, L.S. 2008. Variações na composição florística e na estrutura fitossociológica de uma floresta ombrófila densa alto-montana na Serra da Mantiqueira, Monte Verde, MG. Revista Brasileira de Botânica 31: 559-574.

Meireles, L.D. 2009. Estudos florísticos, fitossociológicos e fitogeográficos em formações vegetacionais altimontanas da Serra da Mantiqueira Meridional, Sudeste do Brasil. Tese de Doutorado. Universidade Estadual de Campinas, Campinas. 262p.

Meirelles, S.T. 1996. Estrutura da comunidade e características funcionais dos componentes da vegetação de um afloramento rochoso em Atibaia, SP. Tese de Doutorado. Universidade Federal de São Carlos, São Carlos. 250 p.

Meirelles, S.T.; Pivello, V.R. \& Joly, C.A. 1999. The vegetation of granite rock outcrops in Rio de Janeiro, Brazil, and the need for its protection. Environmental Conservation 1: 10-20.

Mentz, L.A. \& Oliveria, P.L. 2004. Solanum (Solanaceae) na região sul do Brasil. Pesquisa 54: 1-327.

Mocochinski, A.Y. \& Scheer, M.B. 2008. Campos de altitude na Serra Paranaense: aspectos florísticos. Floresta 38: 625-640.

Moreira, A.A.N. \& Camelier, C. 1977. Relevo. In: Fundação Instituto Brasileiro de Geografia e Estatística, Rio de Janeiro. Vol. 3. Pp. 1-150.

Murillo-A., J.; Ruiz-P. E.; Landrum, L.R.; Stuessy, T.F.; \& Barfus, M.H.J. 2012. Phylogenetic relationships in Myrceugenia (Myrtaceae) based on plastid and nuclear DNA sequences. Molecular Phylogenetics and Evolution 62: 764-776.

Myers, N.; Mittermeier, R.A.; Mittermeier, C.G.; Fonseca, G.A.B. \& Kent, J. 2000. Biodiveristy hotspots for conservation priorities. Nature 403: 853-858.

Nascimento, F.H.F.; Giulietti, A.M. \& Queiroz, L.P. 2010. Diversidade arbórea das florestas alto montanas no sul da Chapada Diamantina, Bahia, Brasil. Acta Botanica Brasilica 24: 674-685.

NYBG - New York Botanical Garden. 1996-2004. The C.V. Starr Virtual Herbarium. Disponível em $<$ http:// sciweb.nybg.org/science2/VirtualHerbarium.asp>. Acesso em 10 junho 2014.

Oliveira-Filho, A.T. \& Fontes, M.A.L. 2000. Patterns of floristic differentiation among Atlantic Forest in southeastern Brazil and the influence of climate. Biotropica 32: 793-810. 
Oliveira-Filho, A.T. \& Ratter, J.A. 2000. Padrões florísticos das matas ciliares da região do cerrado e a evolução das paisagens do Brasil Central durante o Quaternário Tardio. In Rodrigues, R.R. \& LeitãoFilho, H.F.L. (eds.). Matas ciliares: conservação e restauração. Edusp, São Paulo. 73-89.

Peron, M.V. 1989. Listagem preliminar da flora fanerogâmica dos campos rupestres do Parque Estadual do Itacolomi - Ouro Preto/Mariana, MG. Rodriguésia 67: 63-69.

Polisel, R.T.; Ivanauskas, N.M.; Assis, M.C.; Shepherd, G.J. \& Yamamoto, K. 2014. Structure of the understory community in four stretches of Araucaria forest in the state of São Paulo, Brazil. Acta Botanica Brasilica 28: 86-101.

Rambo, B.A. 1956. A flora fanerogâmica dos Aparados Riograndenses. Anais Botânicos do Herbário Barbosa Rodrigues 7: 235-298.

Reginato, M. 2011. A new species of Leandra (Melastomataceae, Miconieae) from Atlantic Forest, Southeastern Brazil. Phytotaxa 33: 46-50.

Ribeiro, K.T.; Medina, B.M.O. \& Scarano, F.R. 2007. Species composition and biogeographic relations of the rock outcrop flora on the high plateau of Itatiaia, SE-Brazil. Revista Brasileira de Botânica 30: 623-639.

Robim, M.J.; Pastore, J.A.; Aguiar, O.T.; \& Baitello, J.B. 1990. Flora arbóreo arbustiva e herbácea do Parque Estadual de Campos do Jordão, SP. Revista do Instituto Florestal 2: 31-53.

Safford, H.D. \& Martinelli, G. 2000. Southeast Brazil. In: Bartlott, W. \& Porembski, S. (eds.). Inselbergs: biotic diversity of isolated rouck outcrops in Tropical and Temperate regions. Springer, Alemanha. Pp. 339-389.

Safford, H.D. 1999. Brazilian Páramos I. An introduction to the physical environment and vegetation of the campos de altitude. Journal of Biogeography 26: 693-712.

Safford, H.D. 2007. Brazilian Páramos IV. Phytogeography of the campos de altitude. Journal of Biogeography 34: 1701-1722.

Santos, M.F.; Serafim, H. \& Sano, P.T. 2011. Fisionomia e composição da vegetação florestal na Serra do Cipó, MG, Brasil. Acta Botanica Brasilica 25: 793-814.

Sarthou, C. \& Villiers, J. 1998. Epilithc plant communities on inselbergs in French Guiana. Journal of Vegetation Science. 9: 847-860.
Scheer, M.B.; Mocochinski, A.Y. \& Roderjan, C.V. 2011. Estrutura arbórea da floresta ombrófilas altomontana de serras do sul do Brasil. Acta Botanica Brasilica 25: 735-750.

Segadas-Vianna, F. \& Dau, L. 1965. Ecology of the Itatiaia range, southeastern Brazil. II - Climates and altitudinal climatic zonation. Arquivos do Museu Nacional 53: 31-53.

Semir, J. 1991. Revisão taxonômica de Lychnophora Mart. (Vernoniaceae: Compositae). Tese de doutorado, Universidade Estadual de Campinas, Campinas.

Smith, L.B. 1962. Origins of the flora of southern Brazil. Contributions from the United States National Herbarium 35: 215-249.

Shepherd, G.J. 1995. Estudo da diversidade de espécies de Spermatophyta (fanerógamas) do estado de São Paulo. In: Bicudo, C.E.M. \& Shepherd, G.J. (orgs.). Biodiversidade do estado de São Paulo, Brasil: síntese do conhecimento ao final do século XX. Vol 2. Fungos macroscópicos e plantas. FAPESP, São Paulo. Pp. 63-76.

Stehmann, J.R. 1998. Estudos taxonômicos na tribo Nicotianeae G.Don (Solanaceae): revisão de Petunia Jussieu, das espécies brasileiras de Calibrachoa La Llave \& Lexarza e o estabelecimento do no gênero Petuniopsis Stehmann \& Semir. Tese de Doutorado. Universidade Estadual de Campinas, Campinas. $216 \mathrm{p}$.

Vasconcelos, M.F. 2011. O que são os campos rupestres e campos de altitude nos topos das montanhas no Leste do Brasil? Revista Brasileira de Botânica 34: 241-246.

Veloso, H.P. 1992. Sistema fitogeográfico. In: Manual técnico da vegetação brasileira. IBGE, Rio de Janeiro. 92p.

Vidal, W.N. \& Vidal, M.R.R. 1995. Botânica-organografia. Impressa Universitária, Viçosa. 114p.

Yamamoto, L.F. 2009. Florística e fitossociologia de espécies arbóreas ao longo de um gradiente altitudinal no extremo sul da Serra da Mantiqueira (Serra do Lopo) MG/SP. Tese de Doutorado. Universidade Estadual de Campinas, Campinas, 156p.

Willis, E.O. 1996. Estimating diversity in Brazilian birds: in the Mantiqueira Range. In: Bicudo, C.E. \& Menezes, N.A. (orgs.). Biodiversity in Brazil: a first approach. CNPq, São Paulo, Pp. 297-307. 
